\title{
Learning enhances behaviorally relevant representations in apical dendrites
}

\author{
Sam E. Benezra ${ }^{1,3,4}$, Kripa B. Patel ${ }^{2,3,4}$, Citlali Pérez Campos ${ }^{2,3,4}$, Elizabeth M.C. Hillman ${ }^{1,2,3,4}$, and \\ Randy M. Bruno ${ }^{1,3,4,5^{*}}$
}

${ }^{1}$ Department of Neuroscience, Columbia University, New York, NY 10027

${ }^{2}$ Departments of Biomedical Engineering and Radiology, Columbia University, New York, NY 10027

${ }^{3}$ Kavli Institute for Brain Science, Columbia University, New York, NY 10027

${ }^{4}$ Zuckerman Mind Brain Behavior Institute, Columbia University, New York, NY 10027

${ }^{5}$ Lead contact

* Correspondence: randybruno@columbia.edu (R.M.B.) 


\section{SUMMARY}

Learning alters cortical representations and improves perception. Apical tuft dendrites in Layer 1, which are unique in their connectivity and biophysical properties, may be a key site of learninginduced plasticity. We used both two-photon and SCAPE microscopy to longitudinally track tuftwide calcium spikes in apical dendrites of Layer 5 pyramidal neurons as mice learned a tactile behavior. Mice were trained to discriminate two orthogonal directions of whisker stimulation. Reinforcement learning, but not repeated stimulus exposure, enhanced tuft selectivity for both directions equally, even though only one was associated with reward. Selective tufts emerged from initially unresponsive or low-selectivity populations. Animal movement and choice did not account for changes in stimulus selectivity. Enhanced selectivity persisted even after rewards were removed and animals ceased performing the task. We conclude that learning produces long-lasting realignment of apical dendrite tuft responses to behaviorally relevant dimensions of a task.

\section{INTRODUCTION}

Learning and memory depend on the ability of biological networks to alter their activity based on past experience. For example, as animals learn the behavioral relevance of stimuli in a sensory discrimination task, neural representations of those stimuli are enhanced (Beitel et al., 2003; David et al., 2012; Fritz et al., 2003; Goltstein et al., 2013; Henschke et al., 2020; Liu et al., 2020; Poort et al., 2015), potentially improving the salience of information relayed to downstream areas. Studies in primary somatosensory (S1) (Banerjee et al., 2020) and visual cortex (Liu et al., 2020) have revealed that top-down signals from distant cortical regions can modify sensory representations during learning, although the cellular and circuit mechanisms underlying this plasticity remain unclear.

Cortical layer 1, comprised mainly of apical tuft dendrites of layer 5 (L5) and layer $2 / 3$ pyramidal neurons, may be a key site driving the enhancement of sensory representations during learning. Apical tufts are anatomically well positioned for learning, receiving top-down signals from numerous cortical and thalamic areas (Cauller et al., 1998; Rubio-Garrido et al., 2009; Zhang and Bruno, 2019). While L5 distal tufts are electrically remote and far from the soma, they are in close proximity to the highly electrogenic calcium spike initiation zone at the main bifurcation of the apical dendrite, and form a separate biophysical and processing compartment from the proximal dendrites (Amitai et al., 1993; Larkum et al., 2009; Sandler et al., 2016; Schiller et al., 1997; Yuste et al., 1994). Top-down signals arriving at the tuft can trigger tuft-wide dendritic calcium spikes in L5 neurons (Manita et al., 2015), which can modulate synaptic plasticity across the entire dendritic tree (Roelfsema and Holtmaat, 2018) and potently drive somatic burst firing (Larkum et al., 2009; Larkum et al., 2004; Larkum and Zhu, 2002; Larkum et al., 2001; Manita et al., 2017; Schwindt and Crill, 1999). Consistent with this observation, L5 apical dendrite activity is highly correlated with somatic activity (Beaulieu-Laroche et al., 2019; Francioni et al., 2019). Therefore, by strongly influencing somatic activity, L5 apical dendritic calcium spikes can play an important role in modulating cortical output. Several neuromodulators can augment the excitability of the apical tuft and increase the likelihood of eliciting calcium spikes (Brombas et al., 2014; Labarrera et al., 2018), which could be a substrate for control of plasticity by behavioral state. Consistent with these ideas, we recently demonstrated that during behavioral training with positive reinforcements, apical tufts in sensory cortex acquire associations that extend beyond their normal sensory modality (Lacefield et al., 2019). In mouse models of dementia and Alzheimer's disease (Luebke et al., 2010; Tsai et al., 2004), tuft dendrites exhibit degeneration which may contribute to the cognitive and memory deficits. 
L5 pyramidal neurons are the major source of output from cortex, targeting numerous subcortical structures that affect behavior. The activity of apical dendrites is known to correlate with stimulus intensity, and manipulating L5 apical dendrites and their inputs impacts performance of sensory tasks (Manita et al., 2015; Takahashi et al., 2020; Takahashi et al., 2016; Xu et al., 2012). Apical dendritic calcium spikes of pyramidal cells could be a crucial cellular mechanism in learningrelated plasticity and behavioral modification (Bittner et al., 2017; Roelfsema and Holtmaat, 2018). However, sensory representations of apical tufts, as well as possible changes across learning, have received little attention.

To address this question, we used two-photon microscopy and a new high-speed volumetric imaging technique called Swept Confocally-Aligned Planar Excitation (SCAPE) (Bouchard et al., 2015; Hillman et al., 2018) to longitudinally track the activity of GCaMP6f-expressing L5 apical tufts in barrel cortex during a sensory discrimination task. We found that apical tufts underwent extensive dynamic changes in selectivity for task-relevant stimuli as performance improved, even though only one of the stimuli was unrewarded. These changes in responses persisted even after animals disengaged from the task, demonstrating that learning induced long-lasting changes in tuft sensory representations. Animals that were exposed to the same stimulation protocol without any reinforcement did not develop enhanced representations. Our results show for the first time that reinforcement learning expands apical tuft sensory representations along behaviorally relevant dimensions.

\section{RESULTS}

\section{Direction discrimination behavior}

We devised an awake head-fixed mouse conditioning paradigm that enables controlled investigation of reinforcement effects across learning (Fig.1A,B). In addition to discriminating tactile objects, rodents are known to sense wind direction using their whiskers (Yu et al., 2016a; $\mathrm{Yu}$ et al., 2016b) and can be trained to discriminate different directions of whisker deflections (Bernhard et al., 2020; Nakamura et al., 2009). With this in mind, we directed brief (100-ms) air puffs at the whiskers in either of two directions: rostrocaudal (backward) or ventrodorsal (upward). One of the directions was paired with a water reward delivered $500 \mathrm{~ms}$ after the air puff and thus constituted a conditioned stimulus (CS+). No reward was given for the other direction (CS-).

Licking and whisking were monitored throughout the session (Fig.1C,D). Stimuli elicited a brief passive whisker deflection followed by active whisking over the subsequent $\sim 1.5$ seconds (analyzed below, Fig.6). Any anticipatory licks prior to reward delivery were counted as a response. Typically, on the first session, mice exhibited few anticipatory licks to either stimulus (Fig.1C, top, grey shading). By session 2 or 3, mice had learned an association between whisker deflection and reward, but could not discriminate the CS+ and CS- (middle). Within a week (by sessions 7-9), every mouse we tested learned to reliably lick to the CS+ while withholding licks to the CS-, performing substantially above chance after a single week of training (Fig.1C, bottom; Fig.1E,F). Thus, mice rapidly learned to discriminate the direction of whisker stimuli in our behavioral task.

\section{Overall stimulus-evoked activity is unbiased and stable across conditioning}

To investigate the effects of reinforcement learning on apical tuft activity, we imaged apical tufts ( $433 \times 433 \mu \mathrm{m}$ field of view) across conditioning days as well as on an unrewarded pre-conditioning day to measure naïve stimulus responses and an unrewarded post-conditioning day to detect any long-lasting changes in responses (Fig.1B). We virally delivered the gene for Cre-dependent GCaMP6f (Chen et al., 2013) in the barrel cortex of Rbp4-Cre mice, which labels a heterogeneous population of pyramidal neurons comprising approximately $50 \%$ of layer 5 (Glickfeld et al., 2013; Kozorovitskiy et al., 2012; Lacefield et al., 2019). By targeting our injections to layer 5B, we 
predominantly labeled thick-tufted pyramidal neurons (see Methods). Using intrinsic signal imaging, we mapped the location of the C2, D2, and gamma whisker barrel columns and identified an overlapping region in layer 1 with sufficient GCaMP6f expression (Fig.2A). The air puff nozzles were aimed toward the whiskers corresponding to this region. Dendritic activity was longitudinally recorded from the same field-of-view (horizontal location and depth) in L1 across all sessions (Supplementary Movie 1).

To extract calcium signals from individual cells, we segmented tufts using CaImAn, a sparse nonnegative matrix factorization method that clusters pixels according to their temporal correlation (Giovannucci et al., 2019) (see Methods), and analyzed regions of interest exhibiting apical tuft structure (Fig.2B; $65 \pm 15$ tufts per mouse; mean $\pm \mathrm{SD}$ ). Individual segmented tufts were substantial in their spatial extent $(>100 \mu \mathrm{m})$, reflecting tuft-wide voltage-gated calcium spikes rather than branch-specific N-methyl-D-aspartate (NMDA) receptor-mediated spikes. All calcium analyses hereafter refer to tuft-wide calcium spikes. Average responses to an event include failures. In many tufts, the CS+ and CS- reliably evoked an influx of calcium that robustly activated the tuft (e.g. Fig.2C). Interestingly, during intermediate but not early learning, the average population response to the CS+ exhibited a two-peak structure (Supp Fig.1, session 4) similar to tuft reward-related signals we observed previously in barrel cortex (Lacefield et al., 2019). By the last-rewarded and post sessions, the second CS+ peak was no longer visible, which could be an endpoint of mice learning that the conditioned stimulus predicts the upcoming reward.

Reward can alter somatic receptive fields in the auditory, visual, and somatosensory cortex of both rodents and non-human primates such that rewarded stimulus representations become more robust after learning (Beitel et al., 2003; Goltstein et al., 2013; Lacefield et al., 2019; Pakan et al., 2018), although cortical sensory responses can remain unchanged during learning (Wang et al., 2020). We investigated whether calcium responses to the CS+ increased in the tuft population as animals learned its association with reward. Average responses of tufts to the CS+ and CS- were similar during the pre-conditioning session (Fig.2D; $p=0.20$, signed rank test), indicating that there was no inherent bias in the population toward a particular stimulus in naïve animals. Surprisingly, even after learning, responses to the CS+ and CS- were similar on the last- and post-conditioning sessions ( $p=0.62,0.64$, respectively, signed rank test), revealing that no bias develops for the CS+ among dendritic tufts. Only a minority of tufts exhibited statistically significant average responses to air puff stimuli (CS+ responsive: $26 \pm 8 \%$; CS- responsive: $25 \pm 8 \%$; mean \pm SD across all sessions). When we excluded responses that were not statistically significant (see Methods), we again found no difference between the average response amplitudes to the CS+ and CS- on the pre, last-rewarded, and post sessions $(\mathrm{p}=0.65,0.31$, and 0.69 , respectively, rank sum test; data not shown). Similarly, the probability of transients in response to CS+ versus CS- (see Methods) did not differ during pre-conditioning $(p=0.66)$ or post-conditioning sessions $(p=0.44)$. Therefore, reinforcement learning in our paradigm does not bias tuft representations toward the rewarded stimulus.

While a bias for the CS + did not develop after learning, we wondered whether overall tuft responses to both conditioned stimuli increased as animals learned the task. Linear regression analysis revealed that conditioning session number was a poor predictor of both CS+ and CS- amplitudes (All tufts R ${ }^{2}$, CS+: 0.0064, CS-: 0.0035, Fig.2E; Significantly responding tufts $\mathrm{R}^{2}, \mathrm{CS}+:$ : 0.014, CS: 0.014, data not shown). We did find a small but significant decrease in amplitude from pre to last for CS+ $(\mathrm{p}<0.01)$ and $\mathrm{CS}-\left(\mathrm{p}<10^{-7}\right)$, but this was not permanent: amplitudes did not significantly differ between the pre and post sessions (Fig.2D; $\mathrm{p}=0.53,0.33$, CS+ and CS- respectively, Wilcoxon rank sum test). Taken together, these findings demonstrate that reinforcement learning does not robustly bias the magnitudes of tuft calcium responses to either stimulus at the population level. 


\section{Development of tuft selectivity with task learning}

While learning produced no bias in overall tuft activity, learning might enhance selectivity for conditioned stimuli. Barrel cortex neurons are tuned to the angle of whisker deflection (Bruno et al., 2003; Bruno and Sakmann, 2006; Ramirez et al., 2014), indicating that the sets of synaptic connections activated by the CS+ and CS- may be overlapping but should not be identical. Therefore, the possibility exists that responses to the CS+ and CS- can change independently of each other. To examine this, we compared the amplitude of the average response to CS+ and CStrials for all segmented tufts on the pre, last-rewarded, and post sessions (Fig.3A; $n=7$ mice; 465 pre, 442 last-rewarded, and 430 post tufts). In agreement with our previous analysis, we found no significant bias toward CS+ or CS- during any of the three sessions (Pre: $p=0.20$; last-rewarded: $\mathrm{p}=0.43$; Post: $\mathrm{p}=0.64$, sign-rank test). Under naïve conditions during the pre session, most tufts that responded to air puff stimuli did not strongly prefer the CS+ or CS- (Fig.3A, left). Surprisingly, on the last-rewarded session and the unrewarded post-conditioning session, we observed a prominent shift in the response distribution, where many tufts exhibited more selective responses to one stimulus or the other (Fig.3A, middle and right).

Plasticity can occur after repeated exposure to stimuli even in the absence of reinforcements (Chu et al., 2016; Dragoi et al., 2002; Dragoi et al., 2000; Yao and Dan, 2001; Zhang et al., 2015). To test whether enhanced selectivity depended on reinforcement, we imaged a separate group of mice that were repeatedly exposed to the same stimuli for the same number of days but without any reward. Repeated exposure mice exhibited a stable distribution of response selectivity over time (Fig.3B; $\mathrm{n}=7$ mice; 317, 313, and 321 tufts on Day 1, Day 8, and Day 9, respectively). These results suggest that reinforcement learning, and not simply repeated stimulus exposure, drives apical tufts to become more selective for either the CS+ or CS-.

To directly quantify the response selectivity of tufts, we computed a selectivity index (SI; see Methods) ranging from -1 (exclusively CS- responsive) to 1 (exclusively CS + responsive) for each tuft. Initially in both the conditioned and repeated exposure mice, the SI distribution was centered around zero, indicating that most tufts in naïve animals did not strongly prefer either stimulus (Fig.3C,D, left panels). Consistent with our other analyses (Fig.2D), the mean SI remained close to zero for each of the three sessions $(-0.049,-0.001$, and 0.003 for pre-conditioning, last rewarded, and post-conditioning days, respectively), confirming that learning produced no overall bias toward one particular stimulus among the population. During learning, the SI distribution of conditioned but not repeated exposure mice shifted markedly, whereby a much greater proportion of neurons were highly selective for either the CS + or CS- (Fig.3C,D, middle and right panels, $|\mathrm{SI}|$ pre versus last-rewarded: $\mathrm{p}<10^{-6},|\mathrm{SI}|$ pre versus post: $\mathrm{p}<10^{-5}$; Wilcoxon rank sum test). These effects can even be observed within individual mice, with learning significantly increasing tuft selectivity in individual conditioned mice, but not repeated exposure mice (Supp.Fig.2). The degree of enhancement in tuft selectivity was closely correlated with conditioned animals' ability to discriminate stimuli across sessions (Fig.3E; Pearson's $\mathrm{R}=0.60, \mathrm{p}<10^{-5}$ ).

Whereas selectivity magnitude ( $|\mathrm{SI}|)$ only considers the amplitude of tuft responses to CS+ and CS, their discriminability also depends on their variability. For example, a large difference in CS + and CS- responses would not be discriminable if the variability of those responses were very high; a small difference might be discriminable if the variability were low. We therefore additionally calculated a d-prime metric of neural discriminability that normalizes differences in response magnitudes to each stimulus by their variability (see Methods). In conditioned animals, neural discriminability of CS+ and CS- responses of tufts increased significantly across learning (Fig.3F, blue; first-rewarded versus last-rewarded: $\mathrm{p}<10^{-3}$, pre versus post: $\mathrm{p}<10^{-4}$; Wilcoxon rank sum 
204

205

206

207

208

209

210

211

212

213

214

215

216

217

218

219

220

221

222

223

224

225

226

227

228

229

230

231

232

233

234

235

236

237

238

239

240

241

242

243

244

245

246

247

248

249

250

251

252

253

254 slightly with progressive exposure to the stimuli (Fig.3F, gray; Day 1 versus Final: $\mathrm{p}<0.01$ ). Taken together, these results show that enhanced stimulus representations can emerge in apical tufts, but require reinforcement.

The above analyses rely on the accurate measurement of calcium spikes from individual tufts. While two-photon microscopy acquires images with high resolution and speed, the imaging field is restricted to a single focal plane. This method can only measure calcium signals from a thin cross-section of the three-dimensionally complex apical structures. Indeed, many of the spatial components extracted from our two-photon data were comprised of dendritic branches that cross the imaging plane at different locations (Supp.Fig.3A), which makes it difficult to determine whether the segmentation software accurately extracted signals from one tuft or erroneously merged multiple tufts. For the same reasons, a single apical tuft could be falsely classified as two different tufts. Such errors could mislead our interpretation of selectivity in the population, especially given that a single apical tuft can exhibit non-homogenous branch-specific events (Cichon and Gan, 2015; Larkum et al., 2009; Palmer et al., 2014).

To confirm that our interpretation was not due to segmentation errors, we repeated the conditioning experiment using a new, high-speed volumetric imaging approach called SCAPE (Bouchard et al., 2015; Hillman et al., 2018), which allowed us to monitor calcium across entire apical tufts (Supplementary Movie 2). These three-dimensional datasets $(300 \times 1050 \times 234 \mu \mathrm{m}$ field of view) encompassed large portions of the apical tree which included branches converging on their bifurcation points in layer 2, enabling us to identify whole apical trees unambiguously (Fig.4A,B; Supp.Fig.3B). CaImAn effectively demixed overlapping trees in these three-dimensional volumes. Using SCAPE microscopy, we imaged tuft activity of additional mice conditioned with the same behavioral paradigm (Fig.4C). Comparison of tuft responses to the CS+ and CS- on the pre, lastrewarded, and post sessions (Fig.4D; 241 pre, 215 last-rewarded, 150 post tufts in 2 mice) revealed again that task learning induced significant increases in tuft selectivity (Fig.4E; pre versus lastrewarded: $\mathrm{p}<10^{-5}$, pre versus post: $\mathrm{p}<10^{-4}$, Wilcoxon rank sum test of $\left.|\mathrm{SI}|\right)$. On average, the SI magnitudes were similar between tufts imaged using 2-photon microscopy and SCAPE (mean \pm s.e.m. $|\mathrm{SI}|$ for 2 -photon versus SCAPE; pre: $0.41 \pm 0.01$ versus $0.40 \pm 0.02$; last-rewarded: $0.54 \pm 0.02$ versus $0.54 \pm 0.02$; post: $0.51 \pm 0.02$ versus $0.53 \pm 0.03$ ). These data demonstrate that the effects in our two-photon dataset are not caused by errors in segmentation, but rather reflect changes at the level of individual dendritic tufts. Our results, based on two different imaging approaches, clearly demonstrate that reinforcement increases stimulus selectivity at the level of the entire apical tuft.

\section{Selective tufts emerge from both initially unresponsive and responsive populations}

The striking effect of reinforcement learning on tuft response selectivity could develop in several ways. For example, initially unresponsive tufts could develop a robust response to either stimulus after learning (e.g., Fig.5A, top). Conceivably, tufts that were initially unselective in naïve animals could also maintain their response to one stimulus while losing their response to the other (e.g., Fig.5A, middle). Either or both scenarios could lead to the increase in neurons that are selective for stimulus direction. To investigate which changes in individual tufts underlie population-wide improvements in stimulus selectivity, we longitudinally tracked the same set of tufts across all sessions and compared their selectivity in pre- and post-conditioning sessions for both conditioned and repeated exposure mice.

First, we categorized tufts that were unresponsive to either stimulus on the first imaging session, which accounted for the large majority of tufts (conditioned: 458/603; repeated exposure: 334/457), and compared their response to the CS+ and CS- on the last session to determine if they became selective (Fig.5B, see Methods). Stimulus-unresponsive tufts, while on average less active than responsive ones (median calcium events per minute: 2.65 versus 3.66 for stimulus-unresponsive 
255

256

257

258

259

260

261

262

263

264

265

266

267

268

269

270

271

272

273

274

275

276

277

278

279

280

281

282

283

284

285

286

287

288

289

290

291

292

293

294

295

296

297

298

299

300

301

302

303

304

305 and responsive tufts, respectively; $\mathrm{p}<10^{-40}$, Wilcoxon rank sum test; Supplementary Fig.4), were not silent, with many undergoing tuft-wide calcium influx several times per minute. Silent tufts that are never active during the session may not have been detected in our imaging, but we were able to detect tufts that discharged as few as 3 voltage-gated calcium spikes over a 30-minute behavioral session. Interestingly, in both the conditioned and repeated exposure mice, approximately $40 \%$ of initially unresponsive tufts developed a response to at least one stimulus by the last session, becoming either selective or unselective (Fig.5B). However, in conditioned animals, the proportion of initially unresponsive tufts that became selective was significantly larger than in repeated exposure mice ( $p<0.05,2$-sample t-test comparing subjects). Furthermore, while the proportion of selective and unselective tufts in this category was similar for conditioned animals, unselective tufts were more common in repeated exposure mice $(\mathrm{p}<0.05$, paired $\mathrm{t}$-test).

Next, we analyzed tufts that were initially responsive and either selective (Fig.5C; conditioned: 56/603, RE: 43/457) or unselective (Fig.5D; conditioned: 89/603, repeated exposure: 80/457). In these smaller categories, we found no significant differences in the outcome of selectivity between the two groups of animals. Together, these results indicate that, while both stimulus exposure and reinforcement can alter tuft tuning, the presence of reward increases the likelihood that initially unresponsive tufts develop selectivity for either the CS+ or CS- (summarized in Fig.5E).

While a greater proportion of tufts from the conditioned animals were selective during the final session (20.2\% versus $10.3 \%$ of tufts from conditioned and repeated exposure mice, respectively), we wondered whether conditioning also impacted the degree of selectivity. First, we compared the SI of initially unresponsive tufts on the final imaging session (Fig. 5F). Supporting our results in Fig. 5B, the SI distribution was shifted toward the tails in conditioned, but not repeated exposure mice, indicating that reward enhances selectivity for either the CS+ or CS- in this subset $(|\mathrm{SI}|$ conditioned versus repeated exposure: $\mathrm{p}<10^{-5}$, Wilcoxon rank sum test).

Next, we compared the $|\mathrm{SI}|$ of all tufts that were categorized as selective during the last imaging session in conditioned and repeated exposure mice (Fig. 5G). Interestingly, we found that even among selective tufts, the $|\mathrm{SI}|$ distribution in conditioned mice was significantly greater than in repeated exposure mice ( $\mathrm{p}=0.006$, Wilcoxon rank sum test), indicating that while selective tufts are present after both conditioning and repeated stimulus exposure, the magnitude of selectivity is stronger after conditioning.

We then quantified the change in $|\mathrm{SI}|$ of all tufts that were responsive in both the first and last sessions by computing the difference between the two sessions (Fig. $5 \mathrm{H}$ ). Tufts in conditioned mice exhibited a greater increase in $|\mathrm{SI}|$ across sessions compared to repeated exposure mice $(\mathrm{p}=0.01$, Wilcoxon rank sum test), demonstrating that the magnitude of selectivity in initially responsive tufts increases after reinforcement learning.

Finally, we found that the SI of tufts that eventually became unresponsive on the last session was similar between the two groups (Fig.5I, $|\mathrm{SI}|$ conditioned versus repeated exposure: $\mathrm{p}=0.06$, Wilcoxon rank sum test). Therefore, the loss of stimulus responsivity that occurred in many tufts cannot account for differences in selectivity after conditioning or repeated exposure, which must instead involve tufts that maintain or acquire selectivity. In summary, our longitudinal analyses revealed that reinforcement learning biases initially unresponsive tufts toward becoming selective and enhances the selectivity of tufts that are initially responsive.

\section{Neither movement nor behavioral choice account for enhanced selectivity}

Several plausible factors could underlie the changes in selectivity we observed across learning. For instance, movements like whisking are correlated with layer 5 somatic action potentials (de Kock 
306

307

308

309

310

311

312

313

314

315

316

317

318

319

320

321

322

323

324

325

326

327

328

329

330

331

332

333

334

335

336

337

338

339

340

341

342

343

344

345

346

347

348

349

350

351

352

353

354

355

356 and Sakmann, 2009; Derdikman et al., 2006; Rodgers et al., 2021) and might have impacted calcium activity in the apical tuft. To investigate whether whisking could account for the changes in tuft selectivity, we imaged the whiskers with a high-speed camera and computed whisking amplitude (see Methods) while mice underwent conditioning and two-photon imaging (Fig.6A). First, we considered whether animals changed their whisker movements in response to conditioned stimuli over the course of learning. We computed the peak of the mean stimulus-aligned whisking amplitude for the CS+ and CS- (Fig.1C, left; Fig.6B) for each session. Although conditioning alters licking behavior (Fig.1C,E), the magnitudes of whisker movements following both stimuli were stable across sessions (Fig.6B; $\mathrm{CS}+: \mathrm{p}=0.44$; CS-: $\mathrm{p}=0.45$; linear regression). We also computed the standard deviation (SD) of stimulus-evoked whisker amplitude across trials for all mice and sessions (Fig. 6C). While the whisking amplitude became slightly more reliable (decreased SD) across sessions $\left(\mathrm{p}<10^{-4}\right)$, the change in reliability across sessions was similar for CS + and CS- ( $p$ $=0.53)$. Therefore, whisking is similar on both trial types throughout learning.

We next examined whether whisking was correlated with tuft calcium activity by comparing stimulus-triggered averages and intertrial interval (ITI) whisk-triggered averages of all tufts during post-conditioning. Whisking amplitude was similar between spontaneous ITI whisking bouts and evoked whisking responses to stimuli ( $\mathrm{p}=0.53$, Wilcoxon rank sum test). In contrast to air puff stimuli, ITI whisking bouts were not associated with a robust calcium response (Fig.6D).

To quantify the relationship of whisking and sensory stimuli to tuft calcium spikes, we performed a linear regression analysis (see Methods) on 322 tufts using calcium influx as the response variable and either stimulus or whisking amplitude as a single predictor variable (Fig.6E). Air puff stimuli more reliably predicted calcium influx than whisking amplitude for each of virtually all tufts $(\mathrm{p}<$ $10^{-12}$, sign rank test). These results are consistent with other studies that found either only weak or no correlation between whisking and L5 tuft calcium spikes in S1 (Lacefield et al., 2019; Takahashi et al., 2020; Xu et al., 2012). Furthermore, we found no relationship between the whisking response and the median SI magnitude on a given session (Fig.6F, whisking to $\mathrm{CS}+\mathrm{p}=0.22$, CS- $\mathrm{p}=0.78$ ). Therefore, changes in whisker movement cannot account for the changes in selectivity during learning that we observed.

Finally, the possibility remains that other task-related signals relaying information about reward expectation and behavioral choice could impact apical tuft activity and drive increases in selectivity. To test this, we compared tuft responses to the CS- in false alarm trials (FA; mouse incorrectly licked for reward) and correct rejection trials (CR; mouse correctly withheld licks) to determine if their activity was modulated by behavioral choice. Notice that these two trial types have the same sensory input but involve different choices. (The corresponding analysis for CS+ trials is not technically possible for lack of sufficient Miss trials after the first conditioning day, an issue also observed in (Poort et al., 2015).) Tufts were classified as behaviorally modulated if the FA response was significantly different from the $\mathrm{CR}$ response, and were not behaviorally modulated if CR and FA responses were statistically indistinguishable (e.g. Fig.7A). Behaviorally modulated tufts accounted for only $\sim 10 \%$ of the total tuft population in both early and late learning (50/395 in early; 35/406 in late learning).

To test whether these behaviorally modulated tufts contributed to increased selectivity during learning, we excluded them and compared selectivity of the remaining behaviorally-insensitive tufts. We found that selectivity increased significantly from early to late learning (Fig.7B,C; median $|\mathrm{SI}|$ of 345 tufts early versus 371 tufts late learning: 0.38 versus $0.47, \mathrm{p}=0.02$, Wilcoxon rank sum test), similar to our previous analysis of the entire population. Licking, like whisking, was a relatively poor predictor of tuft calcium influx (Supp.Fig.5A,B). Because some behaviorally modulated tufts may not have been statistically detectable, we used multivariate linear regression 
to disentangle stimulus responses from licking and whisking, which may have been confounded with choice. Median coefficients for licking and whisking were on average 3.3 times smaller than median stimulus coefficients for the first rewarded, last rewarded, and post sessions (all $\mathrm{p}<10^{-6}$, Wilcoxon rank sum test). Even after we factored out possible effects of movements, CS+ and CScoefficients were enhanced by learning but not repeated exposure (Supp.Fig.5C,D), consistent with our other analyses. Together, these results demonstrate that enhanced selectivity during learning cannot be explained by non-sensory signals related to the animals' behavior.

\section{Enhanced selectivity in barrel cortex is long-lasting when mice exclusively use whiskers}

Mice could conceivably exploit other sensory cues to learn and perform the task, such as auditory cues from the air nozzles or non-whisker tactile cues from air current eddies contacting the fur or skin. To determine which mice exclusively used their whiskers to distinguish the CS+ and CS-, we trimmed all whiskers after the post-conditioning session and assessed performance in five mice. Performance in each of the five mice decreased after whisker trimming, indicating that each used some whisker information. Three mice performed the task exclusively with their whiskers, falling to chance levels after the whisker trim ("whiskers only"). Two other mice still performed the task above chance after the whisker trim, indicating that they were not exclusively using their whiskers and exploited information from multiple sensory streams ("whiskers + other senses").

We examined whether these two different behavioral strategies impacted tuft selectivity. Both the "whiskers only" and "whiskers + other senses" groups exhibited enhanced tuft selectivity in the last-rewarded session relative to pre-conditioning. This effect was more pronounced in the "whiskers only" mice (Fig.8A,B, left and middle; whiskers only: median $|\mathrm{SI}|$ of 180 pre tufts versus 169 last-rewarded tufts: 0.36 versus $0.59, \mathrm{p}<10^{-3}$; "whiskers + other senses": median |SI| of 144 pre tufts versus 155 last-rewarded tufts: 0.39 versus $0.50, p=0.01$ ). Surprisingly, enhanced selectivity persisted during the post-conditioning session for the "whiskers only" group but not the "whiskers + other senses" group (Fig.8A,B right panels; whiskers only: median |SI| of pre versus 167 tufts post: 0.36 versus $0.58 ; \mathrm{p}<10^{-3}$; whiskers + other senses: median $|\mathrm{SI}|$ of 155 pre versus post tufts: 0.39 versus $0.42 ; \mathrm{p}=0.45$ ). Therefore, tuft selectivity in barrel cortex is enhanced regardless of behavioral strategy, but outlasts conditioning only when mice rely solely on their whiskers to perform the task.

We further examined this persistence of enhanced tuft selectivity as experienced mice stopped performing the task. While the entire post-conditioning session was unrewarded, mice initially expected rewards and licked for many CS+ trials in the first half of the session. By the second half of the session, the probability of a lick occurring during the CS+ extinguished, approaching zero (Fig.8C). We compared the selectivity of tufts during the first and second halves of the postconditioning sessions of mice that exclusively used their whiskers and found no difference in the two distributions (Fig.8D, $p=0.94$, Wilcoxon rank sum test of $|\mathrm{SI}|$ ), demonstrating that selectivity of the population remained stable throughout the session. Taken together, these results demonstrate that enhanced stimulus selectivity of apical tuft dendrites after reinforcement learning is long lasting, persisting even after mice cease performing the task and expecting reward.

\section{DISCUSSION}

Our study is the first to investigate how learning a discrimination task alters apical tuft activity. Using both novel volumetric whole-tuft imaging and conventional planar microscopy, we discovered that $\mathrm{L} 5$ apical tufts acquire enhanced representations of multiple stimuli during learning. Rather than simply retuning tufts toward the rewarded stimulus, learning enhanced selectivity for both stimuli, suggesting that tufts are aligning themselves to the behaviorally relevant stimulus dimensions. These enhanced sensory representations persist even after mice cease performing the 
408

409

410

411

412

413

414

415

416

417

418

419

420

421

422

423

424

425

426

427

428

429

430

431

432

433

434

435

436

437

438

439

440

441

442

443

444

445

446

447

448

449

450

451

452

453

454

455

456

457

458 task. In contrast, representations are slightly degraded by mere repeated exposure to stimuli outside of a task. Consistent with previous studies (Lacefield et al., 2019; Xu et al., 2012), we found that movement in and of itself has little direct impact on tuft spikes, indicating that increased selectivity of apicals reflects alterations in sensory coding as animals learn. This sensitization of tufts to behaviorally relevant sensory dimensions may be a general feature of all sensory cortical areas.

Tuft spikes enhance plasticity of synaptic inputs that occur over behavioral (seconds-long) timescales (Bittner et al., 2017; Roelfsema and Holtmaat, 2018). These new behaviorally relevant tuft representations may therefore prime subsequent plasticity of synapses across the entire pyramidal neuron. Additionally, tuft events potently modulate somatic burst firing and enhance how somata respond to their basal inputs (Larkum, 2013; Larkum et al., 2009). As learning and plasticity increase apical selectivity for a behaviorally relevant axis, tuft events will unavoidably amplify somatic burst output along the same axis. This could enable action potential output of L5 cells in primary sensory cortex to directly drive behavioral responses via projections to movement related areas, such as the corticostriatal, corticopontine, and corticotrigeminal pathways. Thus, tuft spikes have the potential to modify somatic output, both in the present and in the future.

\section{Enhanced Representation of Behaviorally Relevant Stimuli}

Enhancing the representation of relevant stimulus dimensions rather than a singularly important stimulus, such as a rewarded event, has multiple benefits for behavior. In our paradigm, both the $\mathrm{CS}+$ and CS- are predictive of whether or not a reward will occur in the future. Explicitly encoding both stimuli could allow sensory cortical areas to directly elicit actions. In the context of this task, $\mathrm{CS}+$ preferring tufts in barrel cortex may trigger anticipatory licking while CS- preferring tufts could suppress licking. L5 cells in sensory cortex via their output to striatum, pons, brain stem, and spinal cord would thereby be able to directly and rapidly drive action without further cortical processing, such as by frontal areas including motor cortex (Park et al., 2020; Takahashi et al., 2020). Such rapid sensory-motor transformations by primary sensory areas may be critical for natural time-constrained behavior.

Furthermore, learning produced a representation in which the degree of selectivity for the two stimuli was continuous and uniformly distributed. Exclusively CS+ or CS- selective apicals never dominated the population. Continuous degrees of selectivity across the population, rather than discrete representations, may allow the system to be more robust to the variability caused by active movements that alter sensory input. A continuous distribution may also facilitate future adjustments of neural representations as subjects continue to learn a task or encounter new tasks. The uniformity we observed may reflect that neurons are high-dimensional, being sensitive to mixtures of variables (Kim et al., 2020; Rigotti et al., 2013; Rodgers et al., 2021; Stringer et al., 2019), only one of which might be altered here by learning. The uniform distribution of selectivity corresponds to a full range of pessimism to optimism concerning stimulus predictions of upcoming rewards. Recent work shows that behavioral performance benefits from reinforcement learning that incorporates the distribution of reward probabilities rather than just the average expected reward value (Dabney et al., 2020). L5 corticostriatal synapses could theoretically afford a plastic substrate for acquiring the necessary distribution of reward probabilities.

Surprisingly, past studies in which mice were trained to associate one or more stimuli with a reward typically show that cortical representations are stronger for the rewarded stimulus (Goltstein et al., 2013; Henschke et al., 2020; Poort et al., 2015). In contrast to these studies of layer $2 / 3$ somatic activity, our experiments revealed that the overall tuft calcium response to the CS+ and CS- at the population level did not change significantly after animals learned the task (Fig.2). Instead, representations for both stimuli were enhanced by individual tufts developing selectivity for either 
459

460

461

462

463

464

465

466

467

468

469

470

471

472

473

474

475

476

477

478

479

480

481

482

483

484

485

486

487

488

489

490

491

492

493

494

495

496

497

498

499

500

501

502

503

504

505

506

507

508

509 the CS+ or the CS- (Fig.3). This divergence in phenomena may result from several important differences between our work and the aforementioned studies.

First, enhanced selectivity for both rewarded and unrewarded stimuli could be a phenomenon that is unique to the apical dendritic tufts. In addition to local inputs, the apical tufts of pyramidal cells in S1 receive long-range top-down input from several sources, including motor cortex (Petreanu et al., 2012; Xu et al., 2012), secondary somatosensory cortex (Cauller et al., 1998), and secondary thalamus (Rubio-Garrido et al., 2009; Wimmer et al., 2010; Zhang and Bruno, 2019). Frontal areas, such as prefrontal cortex, indeed have enhanced representations of the CS+ and CS- after learning (Wang et al., 2020). In contrast, input to the somata is dominated by the local cortical area and primary thalamus (Constantinople and Bruno, 2013; Feldmeyer, 2012). While somato-dendritic coupling can be strong in L5 neurons (Beaulieu-Laroche et al., 2019), it is asymmetric; at least $40 \%$ of somatic transients attenuate in a distance-dependent manner along the apical trunk and distal tufts (Francioni et al., 2019). The non-overlapping anatomical inputs and asymmetric coupling together could produce different learning-related effects on apical tuft and somatic stimulus representations.

Second, learning-related changes may manifest differently in layer $2 / 3$, the usual focus of previous studies (Henschke et al., 2020; Poort et al., 2015), and layer 5 pyramidal cells, the tufts of which we studied. With the exception of a small population of corticostriatal cells, most excitatory cells in layer $2 / 3$ project to other cortical areas to affect further cortical processing (Petersen and Crochet, 2013; Yamashita et al., 2018). In contrast, many L5 cells project to subcortical structures including the thalamus, superior colliculus, and brainstem, which may directly trigger behavioral responses (Krauzlis et al., 2013; Llinas et al., 1998; Parvizi and Damasio, 2001). In discrimination paradigms, both stimuli are relevant to behavior. In our task, the CS+ prompted licking to obtain a reward, and the CS- suppressed licking that would have no benefit. Thus, an enhanced representation of both stimuli in layer 5 would be advantageous for animals to perform the task efficiently. Recently, it was shown that apical dendrite activation of subcortical-targeting pyramidal tract L 5 cells, but not intratelencephalic L5 cells that are more like L2/3 cells in their connectivity, determines the detection of tactile stimuli (Takahashi et al., 2020). The Rbp4-Cre mice we used in this study labels a heterogenous population of layer 5 pyramidal cells, comprising both pyramidal tract and intratelencephalic neurons. In the future, it would be interesting to examine whether learning has different effects on the sensory representations of these two populations. Moreover, direct comparisons of the layers would be particularly informative.

\section{Candidate Plasticity Mechanisms}

Enhanced selectivity could be due to changes in local synaptic connectivity, long-range inputs, or both. Learning may strengthen and weaken synapses onto barrel cortex neurons from ascending thalamocortical input or from neighboring cells. Such local plasticity could enhance CS + or CSresponsiveness. Alternatively or additionally, other cortical regions encoding task context could via long-range inputs reconfigure barrel cortex to respond more strongly to these stimuli. The present results do not completely distinguish between these two scenarios because long-range inputs may still encode the context while the mouse is in the behavioral apparatus. However, we found that enhanced representations persist after mice are no longer engaged in the task and receiving rewards. This result suggests that enhanced representations may be a product of local plasticity in sensory cortex that alters receptive fields.

Even in the absence of reward, repeated exposure to stimuli can drive plasticity in sensory cortex and alter response tuning. For instance, repeated exposure to oriented gratings can alter the orientation tuning of cells in primary visual cortex (Dragoi et al., 2002; Dragoi et al., 2000; Yao and Dan, 2001), and overstimulation of whiskers induces plasticity at dendritic spines and alters 
whisker representations in somatosensory cortex (Feldman and Brecht, 2005; Zhang et al., 2015). Our results demonstrate that at the population level enhanced representations developed only when stimuli were behaviorally relevant. Our longitudinal analysis revealed that while the response dynamics of some tufts changed after repeated stimuli presentations, overall selectivity of the population did not increase when rewards were omitted (Figs.3\&5). This raises the question: What are the mechanisms that drive enhanced selectivity under rewarded conditions? In one possible scenario, reward delivery causes the release of neuromodulators that augment the activity of apical tufts. Cortical layer 1 is innervated by cholinergic afferents from the nucleus basalis (Mechawar et al., 2000) and adrenergic afferents from the locus coeruleus (Freedman et al., 1975), the main source of acetylcholine and norepinephrine, respectively. Salient events such as reward and arousal lead to the release of these neuromodulators in cortex (Chubykin et al., 2013; Thiele and Bellgrove, 2018), which could increase the excitability of apical dendrites by recruiting disinhibitory circuits or directly influencing dendritic currents (Brombas et al., 2014; Chubykin et al., 2013; Hangya et al., 2015; Labarrera et al., 2018). In this model, the release of reward-driven neuromodulators promotes plasticity and an enhanced representation of temporally aligned sensory inputs. This phenomenon was demonstrated in auditory cortex, where tones paired with stimulation of the nucleus basalis shifted the tuning of neurons toward the frequency of the paired stimulus (Froemke et al., 2007).

Why are representations of the CS- equally enhanced when there is no associated reward? One explanation is that, as mice learn that the CS- indicates absence of reward, the CS- effectively signals punishment and acquires negative value. Acetylcholine is released in response to aversive stimuli, and can activate disinhibitory microcircuits that reduce inhibition onto pyramidal cells and may be essential for learning (Gasselin et al., 2021; Letzkus et al., 2011). Thus, it is possible that both the CS+ and CS- representations are enhanced by neuromodulatory mechanisms tied to reward and punishment, respectively. An open question is whether the outcome is due to reinforcement learning or the behavioral state brought on by the reinforcers rather than their valence. Sensory cortical plasticity may not be tied to reinforcer valence. Our paradigm creates an environment where mice benefit from being attentive and engaged in order to maximize reward while minimizing effort. Previous work has shown that active engagement in a visual discrimination task was associated with significantly higher selectivity in layer $2 / 3$ cells in visual cortex (Poort et al., 2015). Task engagement may lead to a sustained increase in neuromodulator release throughout the conditioning session, priming the apical dendrites for plasticity and the development of selective responses for task-relevant stimuli as they learn.

What determines whether a particular tuft eventually becomes selective for the CS+ or CS-? Our longitudinal analysis revealed that many tufts that were initially unresponsive to either stimulus developed a highly selective response to either the CS+ or the CS- (Fig.5). In these tufts, stimulus preference after learning might be seeded by initially weak, directionally selective inputs on to the

549 neuron that already exist prior to conditioning and that are potentiated by the learning process. We also found tufts that initially exhibited robust responses to both stimuli and either lost or significantly reduced their response to one stimulus after learning. The reduction of an apical response to a particular stimulus could be driven by local disynaptic inhibition between L5 pyramidal cells mediated by the apical-targeting Martinotti cells (Berger et al., 2010; Kapfer et al., 2007; Naka and Adesnik, 2016). Through this mechanism, L5 neurons that are selective for a particular stimulus could inhibit responses to that stimulus in neighboring L5 apical tufts. Experiments that assess the tuning of excitatory and inhibitory inputs onto apical dendrites as a function of learning could test such mechanisms.

558

559

560

In addition to demonstrating increased tuft selectivity with learning, we replicated a surprising phenomenon in a previous instrumental behavior in which a population of apical tufts exhibit 
561

562

563

564

565

566

567

568

569

570

571

572

573

574

575

576

577

578

579

580

581

582

583

584

585

586

587

588

589

590

591

592

593

594

595

596

597

598

599

600

601

602

603

604

605

606

607

608

609

610

611

activity around the time of reward (Lacefield et al., 2019). This reward-related activity was observed only during CS+ trials and was most prominent during intermediate conditioning sessions, when most animals were still performing at chance levels, and disappeared completely by the final conditioning session (Supp.Fig.1). Other than this transient effect, unconditioned stimuli did not appear to elicit calcium responses, consistent with our previous findings (Lacefield et al., 2019). The disappearance of this reward-related peak might be attributable to the reward becoming predictable in later stages of learning. In previous classical conditioning experiments, dopaminergic cells exhibit responses to rewards early in learning due to the novelty of an unexpected stimulus. These responses are lost after extended training, as animals learn the association between the CS and reward (Ljungberg et al., 1992; Pan et al., 2005). While dopaminergic terminals are sparse in primary sensory areas, they are not entirely absent, nor are dopaminergic receptors. Furthermore, the excitability of the apical tuft is sensitive to noradrenaline (Labarrera et al., 2018). Interestingly, noradrenergic neurons in the locus coeruleus exhibit a similar phenomenon to dopaminergic neurons, where responses shift from temporal alignment with the reward to a predictive conditioned stimulus after learning (Bouret and Sara, 2004). Such mechanisms could explain why rewardrelated activity is restricted to early-to-intermediate learning in our paradigm.

\section{Global versus local dendritic spikes}

Apical dendrites exhibit not only global spikes that elicit calcium influx across the entire tuft, which we exclusively analyzed here, but also local events known as NMDA spikes, which typically engage short $(<30-\mu \mathrm{m})$ segments of individual dendritic branches (Larkum et al., 2009; Palmer et al., 2014; Xu et al., 2012). These local, NMDA receptor-dependent events can promote prolonged plasticity within individual dendritic branches in the absence of backpropagating actions potentials, a feature that is unique to the apical dendrites (Sandler et al., 2016). In motor cortex, branch-specific NMDA spikes are crucial for establishing the long-lasting plasticity necessary for learning (Cichon and Gan, 2015), and depolarization provided by multiple local NMDA spikes is thought to be essential for the generation of a global calcium spike triggered by distal synaptic inputs (Larkum et al., 2009). We focused this study on global tuft-wide calcium events, rather than local events. Local events are more difficult to unambiguously identify in planar imaging (Sheffield and Dombeck, 2015), and their existence in vivo is still an open question for L5 apicals in barrel cortex (Palmer et al., 2014; Xu et al., 2012). Nonetheless, they may play important roles in plasticity processes that eventually lead to the emergence of global tuft spike selectivity for stimuli. Volumetric microscopy studies, the feasibility of which we showed here, are needed to further investigate the existence of local events in such behaviors as well as examine possible relationships between local and global tuft events during reinforcement learning.

To analyze activity of individual tufts, we segmented these structures based on spatiotemporal covariance (Giovannucci et al., 2019). This method does not discount the possibility of errors where one tuft is split erroneously into two trees, or where two highly correlated tufts are merged. With this in mind, we used volumetric imaging SCAPE microscopy, which allowed us to visualize the apicals in three dimensions and unambiguously screen for such artifacts. The results from SCAPE are quantitatively similar to those from two-photon microscopy, and confirm that our observation of enhanced selectivity with learning is not an artifact of planar imaging.

\section{Stability of learned tuft representations}

In contrast to previous studies of discrimination learning (Henschke et al., 2020; Liu et al., 2020; Poort et al., 2015), we included an unrewarded post-conditioning session to examine whether learning-related effects persisted through extinction. Our results show that post-conditioning selectivity of the apical population remains significantly higher than pre-conditioning, even after animals stop licking in response to the CS+ (Fig.8). Interestingly, the effects of learning are much more pronounced in animals that relied exclusively on their whiskers to perform the task. In animals 
612 that apparently used other sensory modalities, we observed a modest increase from the pre to last-

613 rewarded session, which seemed to be largely absent by the post-conditioning session. Considering

614 that these animals were additionally exploiting other sensory areas to perform, selectivity may have

615 been more widely distributed and thus diluted in barrel cortex, diminishing the effect and its

616 stability. How long selectivity persists in the neuronal population after conditioning and which

617 factors influence stability are interesting open questions for future study.

618

619 Conclusion

620 In summary, we have shown for the first time that reinforcement learning enhances representations

621 along behaviorally relevant dimensions in apical tufts. Our results suggest that dendritic calcium

622 spikes are an important cellular mechanism underlying the changes in sensory encoding that occur

623 with learning, and provide an avenue for further investigation of cellular and circuit mechanisms

624 underlying plasticity induced by perceptual experience and reinforcement. This cellular

625 compartment may be key to understanding pathology in some cognitive, memory, and learning

626 disorders.

627 


\section{ACKNOWLEDGEMENTS}

629 We thank Venkatakaushik Voleti for help with the design, construction, and alignment of the

630 SCAPE microscope; Dan Kato, Georgia Pierce, and Jung Park for help with pilot experiments;

631 Eftychios Pnevmatikakis and Johannes Friedrich for advice on dendrite segmentation; and Larry

632 Abbott, Stefano Fusi, Ashok Litwin-Kumar, Chris Rodgers, Georgia Pierce, Gordon Petty, and Dan

633 Kato for comments on the manuscript. Funding was provided by NIH/NINDS R01 NS069679,

634 NIH/NINDS R01 NS094659, a Grossman-Kavli Scholar Award (RMB), a Kavli Institute for Brain

635 Science Postdoctoral Fellowship (SEB), NIH/NINDS/NIMH/BRAIN U01 NS094296, UF1

636 NS108213, U19 NS104649, and RF1 MH114276 (EMCH).

637

638 AUTHOR CONTRIBUTIONS

639 SEB and RMB conceived of the behavioral and two-photon imaging experiments. EMCH and

640 RMB conceived of the SCAPE imaging experiments. SEB built the behavioral apparatus, EMCH,

$641 \mathrm{KBP}$, and CC designed, built, and maintained the SCAPE microscope, and RMB built and

642 maintained the two-photon and intrinsic signal microscopes. SEB performed the experiments and

643 analyzed the data with input from RMB and EMCH. SEB and RMB wrote the manuscript. 
645

646

647

648

649

650

651

652

653

654

655

656

657

658

659

660

661

662

663

664

665

666

667

668

669

670

671

672

673

674

675

676

677

678

679

680

681

682

683

684

685

686

687

688

689

690

691

692

693

694

\section{MAIN FIGURES}

\section{Figure 1. Mice rapidly learn to discriminate stimulus direction in head-fixed paradigm.}

(A) A water droplet is paired with air puffs in one direction (CS+) but not the other (CS-).

Licking in anticipation of water is assessed in the response window just after CS + or CS- and prior to water delivery for the CS+ (grey bar).

(B) Experimental timeline. 2-3 weeks after virus injection, naive tuft responses to stimuli are recorded (pre). The CS+ is then paired with water for 8-9 days (blue). On the last day, stimuli are presented without reward (post). In a separate group of mice, the same stimuli are presented over 9 days in the absence of reward (unrewarded group).

(C) Lick rasters for three different sessions in one example mouse. On session 9, the CS+ but not the CS- reliably elicits licks.

(D) Mean baseline-subtracted whisking amplitude aligned to the CS+ (red) and CS- (navy) across sessions 1, 2, and 9 of an example mouse.

(E) Learning curve demonstrates rapid learning. Mean probability of at least one lick in the response window across sessions.

(F) Behavioral performance of each mouse in the rewarded group (M1 - M7).

\section{Figure 2. Overall tuft response to stimuli is unbiased and relatively stable across} conditioning.

(A) Dendritic activity was recorded in layer 1 (i) in the $\mathrm{C} 1 / \mathrm{C} 2$ barrel columns (ii). (i) Two-photon image $\sim 60 \mu \mathrm{m}$ deep relative to pia. Dashed yellow lines denote $\mathrm{C} 1$ and $\mathrm{C} 2$ boundaries from intrinsic imaging. Reconstruction from (Ramirez et al., 2014).

(ii) Tangential section through layer 4 showing barrels stained with streptavidin-Alexa 647 and GCaMP6f-expressing apical trunks. Red circles indicate location of 2-photon lesions to mark the imaging region for post-hoc analysis.

(B) Overlay of five segmented pseudo-colored tufts from imaging field in A(i).

(C) Time courses of calcium responses of example tufts in (B) to three air puffs (dashes).

(D) Amplitude for CS+ (red) and CS- responses (blue), computed for each segmented tuft in the first $1.5 \mathrm{~s}$ post-stimulus (grey points), do not differ within or across sessions. Colored lines indicate median.

(E) Same as in D, showing data for all conditioning sessions.

Figure 3. Reinforcement learning, but not stimulus exposure, enhances tuft selectivity for CS+ and CS- stimuli.

(A) Across the indicated sessions, individual tufts (circles) exhibit larger biases to CS + or CS(pooled across all conditioned mice).

(B) Repeated exposure to stimuli does not bias individual tufts to CS+ or CS-.

(C) Conditioning reshapes distribution of selectivity indices for tufts from Normal on preconditioning session to uniform on post-conditioning session.

(D) Distribution of tuft selectivity indices remains Normal throughout all repeated exposure sessions.

(E) Selectivity (median SI magnitude of tufts for each session) increases with behavioral performance of 6 animals.

(F) Neural discriminability (mean \pm sem) of tufts, pooled across all animals on each session, increases with conditioning and decreases with repeated exposure.

Figure 4. High-speed volumetric imaging of apical tufts confirms the emergence of enhanced selectivity after learning.

(A) Top and side view of four example tufts segmented from volumetric SCAPE imaging. 
695 (B) Time courses of calcium activity from example tufts in (A) during five presentations of air puff stimuli (dashes).

698

(C) Performance across all conditioning sessions of two mice that were imaged with SCAPE.

699

(D) Across the indicated sessions, individual SCAPE-imaged tufts (circles) exhibit larger biases

700

701

702

703

704

705

706

to CS+ or CS-.

(E) Conditioning reshapes selectivity distribution from Normal to uniform.

\section{Figure 5. Longitudinal tracking reveals that reward enhances the selectivity of both initially} unresponsive and responsive tufts.

(A) Three example tufts that were longitudinally tracked across learning. Top row: An initially unresponsive tuft develops a robust response to the CS+ but not the CS- after learning. Middle row: A responsive but unselective tuft loses its robust $\mathrm{CS}+$ response and becomes selective for the CS-. Bottom row: A CS- selective neuron becomes unresponsive to both stimuli. (B) Tufts that were unresponsive during the first session were longitudinally tracked to the last session. Plotted is the mean proportion of selective and unselective neurons across all animals in the conditioned (black bars) and repeated exposure (grey bars) groups.

711 (C,D) Same analysis as C for initially selective (D) and unselective (E) tufts.

712 Two-sample t-test was used for comparisons between conditioned and repeated exposure groups.

713 Paired t-test was used for comparisons within a group. $* \mathrm{p}<0.05$

714 (E) Total tuft counts from first to last session within the 3 response categories for either

715 conditioned (left) or repeated exposure (right) groups.

716 (F) SI of responsive tufts on the last session that were initially unresponsive during the first

717 session. Conditioned tufts have enhanced selectivity compared to repeated exposure.

718 (G) Tufts that were selective on the last session are more selective if conditioned (black) rather

719 than undergoing repeated exposure (grey).

720

721

722

723

724 conditioned rather than undergoing repeated exposure.

(I) SI of responsive tufts on the first session that later became unresponsive during the last session.

\section{Figure 6. Whisking is only weakly correlated with tuft activity and cannot account for} changes in selectivity during learning.

(A) Whisking amplitude aligned to calcium activity of three example tufts in one session. Green shading indicates periods of whisking. Red and navy ticks indicate CS + or CS- delivery, respectively.

(B) Mean whisking response of four mice to CS + (red) and CS- (navy) does not change across sessions during learning (mean \pm s.e.m.).

(C) Mean standard deviation of whisking decreases for both CS+ and CS- across learning, but $\mathrm{CS}+$ and CS- do not differ.

(D) Event-triggered averages of 322 tufts on the post-conditioning day (grey traces - individual tufts, black inset - population average) are responsive to stimuli but relatively unmodulated by whisking.

(E) $\mathrm{R}^{2}$ values for linear models predicting calcium from stimuli (y axis) are consistently greater than those predicting calcium from whisking (x axis). Each circle represents a tuft.

(F) Magnitude of tuft selectivity does not correlate with mean whisking amplitude during CS+ (left) and CS- trials (right) on that session.

743

\section{Figure 7. Behavioral responses do not account for enhancement of stimulus selectivity during learning.}


744 (A) Mean stimulus responses of four tufts during hit (red), CR (cyan), and FA (black) trials. Top

745 row: Example tufts whose responses are not behaviorally modulated (CR is similar to FA).

746 Bottom row: Example tufts with behaviorally modulated responses (CR and FA differ).

747 (B) Selectivity index (SI) distribution changes from early (left) and late learning sessions (right)

748 even when tufts with behaviorally modulated responses $(\mathrm{CR} \neq \mathrm{FA})$ are excluded.

749 (C) Median SI magnitude of tufts in each of six animals (from panel B) increases from early to

750 late learning sessions.

751

752

753

Figure 8. Apical tufts in barrel cortex of mice performing the task exclusively with their whiskers undergo long-lasting changes in selectivity.

754 (A) SI histograms of mice performing the task exclusively with their whiskers exhibit increased 755 selectivity across pre-conditioning, last-rewarded, and post-conditioning sessions.

756 (B) Relative to pre-conditioning, mice using their whiskers and other sensory cues to perform the 757 task have increased selectivity during the last rewarded session, but not the post-conditioning 758 session.

759 (C) The probability of anticipatory licks in response to the CS+ extinguishes across post-

760 conditioning blocks (of 20 trials each).

761 (D) Tuft selectively remains uniformly distributed during post-conditioning trial blocks 1-2 (top)

762 while licking is extinguishing, and blocks 3-4 (bottom) in which licking is extinguished.

763

764

765

766

767 


\section{SUPPLEMENTAL FIGURES}

\section{Supplementary Figure 1. CS+ trials evoke a second, long-latency peak during early learning, but not late learning.}

(A) Left: Population average of stimulus-responsive tufts aligned to CS+ (red) or CS- (blue) trials from an example mouse. Right: Normalized $\Delta \mathrm{F} / \mathrm{F}$ of individual tufts during $\mathrm{CS}+$ trials.

(B) Same as in A, combining data across four mice whose imaging regions were mapped with intrinsic imaging.

\section{Supplementary Figure 2. Selectivity was enhanced in individual animals that received rewards. \\ Median SI magnitude for each animal across three sessions for conditioned (left) and repeated exposure groups (right). $* \mathrm{p}<0.05, * * * \mathrm{p}<10^{-3}$}

Supplementary Figure 3. Segmented tufts from two-photon and SCAPE microscopy. $(\mathrm{A}, \mathrm{B}) 12$ example tufts extracted from either two-photon (A) or SCAPE microscopy (B). Tufts segmented from SCAPE microscopy are shown as maximum intensity projections from the top and side. Scale bars: $100 \mu \mathrm{m}$.

\section{Supplementary Figure 4. Calcium event rate of tufts that were either unresponsive or responsive to air puff stimuli. \\ The number of calcium events per minute was quantified for all tufts during each conditioning session. Data from each group was pooled across all sessions.}

Supplementary Figure 5. Licking cannot account for changes in selectivity during learning. (A) ITI lick-bout-triggered averages of 232 tufts on the 5 th conditioning day, when ITI licks were still common (grey traces - individual tufts, black inset - population average), exhibit little or no lick-related calcium influx.

(B) $\mathrm{R}^{2}$ values for linear models predicting calcium from stimuli (y axis) are consistently greater than those predicting calcium from licking ( $\mathrm{x}$ axis). Each circle represents one tuft out of 442 tufts on last-rewarded sessions.

(C) Coefficients from a multivariate regression analysis with calcium as the response variable and the CS+, CS-, whisking, and licking as the predictors. CS+ and CS- coefficients are therefore disentangled from correlations with whisking and licking. Conditioning biases individual tufts (circles) to have larger CS + or CS- coefficients. $\mathrm{n}=304,324$, and 322 tufts for First rewarded, Last rewarded, and Post conditioning, respectively.

(D) Similar analysis to $\mathrm{C}$ but for repeated exposure group, with calcium as the response variable and the CS+, CS-, and whisking as the predictors. $\mathrm{n}=223,208$, and 218 tufts for Day 2, Final - 1, and Final session, respectively.

Supplementary Movie 1. Example two-photon microscopy movie during behavioral session. Playback speed is in real time. "CS+" and "CS-" denote times of stimulus onset. 433 x $433 \mu \mathrm{m}$ field of view.

\section{Supplementary Movie 2. Example SCAPE microscopy movie during behavioral session.} Top, maximum intensity projection (MIP) across the dorsal-ventral dimension showing horizontal extent of dendritic activity. Bottom, MIP across the medial-lateral dimension showing vertical extent of dendritic activity. Playback speed is in real time. "CS+" and "CS-" denote times of stimulus onset. $300 \times 1050 \times 234 \mu \mathrm{m}$ field of view. 
817

818

819

820

821

822

823

824

825

826

827

828

829

830

831

832

833

834

835

836

837

838

839

840

841

842

843

844

845

846

847

848

849

850

851

852

853

854

855

856

857

858

859

860

861

862

863

864

865

866

867

\section{METHODS}

All experiments complied with the NIH Guide for the Care and Use of Laboratory Animals and were approved by the Institutional Animal Care and Use Committee of Columbia University. Sixteen C57BL/6 mice were used in these experiments.

\section{Surgery}

Animals were administered dexamethasone $(1 \mathrm{mg} / \mathrm{kg})$ via intramuscular injection $1-4$ hours prior to surgery to reduce edema. Anesthesia was induced with $3 \%$ isoflurane in oxygen and maintained at $1 \%$. Mice were head-fixed in a stereotax, and a subcutaneous injection of bupivacaine $(0.5 \%, 0.1$ $\mathrm{mL})$ was administered under the scalp. Buprenorphine $(0.05 \mathrm{mg} / \mathrm{kg})$ was injected subcutaneously on the back. The scalp was cut, and the skull was covered with a thin layer of Vetbond. A circular craniotomy (3-mm diameter) centered at $1.5 \mathrm{~mm}$ posterior and $3.5 \mathrm{~mm}$ lateral to bregma was made using a dental drill. The dura was kept moist using artificial cerebrospinal fluid.

Rbp4-Cre_KL100 mice were injected with $100 \mathrm{~nL}$ of virus (initial titer $\sim 2 \times 10^{13} \mathrm{cfu} / \mathrm{mL}$, diluted 1:4 in artificial cerebrospinal fluid) encoding GCaMP6f in a Cre recombinase-specific manner (AAV1CAG-flex-GCaMP6f, UPenn Vector Core). The virus was injected in layer 5B of the barrel cortex $(1 \mathrm{~mm}$ ventral to the pia) using a pulled pipette (20-30 $\mu \mathrm{m}$ ID) fastened on a Nanoject III. This depth was chosen to maximize labeling of thick-tufted pyramidal neurons. In pilot experiments, we found that placing injections $1.0 \mathrm{~mm}$ deep resulted primarily in thick-tufted labeling whereas at more superficial depths (e.g., $0.8 \mathrm{~mm}$ deep), we obtained mainly thin-tufted tufts, consistent with (Oberlaender et al., 2012). The dura was then removed, and a thin cover glass was implanted and sealed using superglue. A custom metal head plate was implanted on the skull using dental cement. Twenty-four hours after surgery, carprofen $(5 \mathrm{mg} / \mathrm{kg}$ ) was administered subcutaneously. Imaging and behavioral training commenced 3 weeks after surgery.

\section{Behavior}

Animals in both rewarded 'conditioning' and unrewarded 'repeated exposure' groups were water restricted for 2 days prior to starting imaging and habituated to head fixation for $\sim 10$ minutes on each of these 2 days. They were subsequently given $\sim 1 \mathrm{~mL}$ of water per day for 9 days either by pairing water rewards with a specific stimulus (conditioning group), or in their cage following the imaging session (repeated exposure group). Mice were head restrained in a custom-made behavioral apparatus by positioning the body in a 3D-printed chamber and fastening the head plate to metal posts flanking the chamber. Air puff stimuli (10 psi measured before a control solenoid, $100 \mathrm{~ms}$ ) were delivered from two nozzles (cut P200 pipette tips) positioned toward the distal tips of the whiskers, in either the rostrocaudal or ventrodorsal direction. Nozzles were oriented to prevent air jets from stimulating other parts of the face. One of these directions (CS+) was paired with a water reward $(10 \mu \mathrm{L})$, delivered through a lick port 0.5 seconds after the stimulus onset. The particular direction (rostrocaudal vs ventrodorsal) used as the CS+ was randomized and counterbalanced across mice. Approximately 180 stimuli were presented over the course of a 30minute imaging session (8-12-s intertrial interval). The probability of CS+ or CS- delivery was $50 \%$. In preliminary experiments, we found that an auditory mask helped prevent mice from exploiting auditory cues to discriminate the two stimuli: a third air nozzle was positioned close to the mouse and was active throughout the session.

During the first session (pre-conditioning), stimuli were delivered in the absence of reward to assess neural and behavioral responses in naïve animals. In the following 7-9 days, the CS+ was paired with reward. Licks for rewards were detected with a capacitance-based touch sensor (Sparkfun). A trial response was registered when one or more licks were elicited within a 0.5 -second response window following the stimulus and before reward delivery. To determine whether behavioral 
868

869

870

871

872

873

874

875

876

877

878

879

880

881

882

883

884

885

886

887

888

889

890

891

892

893

894

895

896

897

898

899

900

901

902

903

904

905

906

907

908

909

910

911

912

913

914

915

916

917

918 performance was above chance, we computed $95 \%$ confidence intervals using the 'binofit' function in MATLAB. During the final session (post-conditioning), stimuli were delivered in the absence of reward. Animals in the unrewarded group received the same two stimuli across 9 days without reward pairing. Behavioral experiments were performed with the Arduino-based OpenMaze opensource behavioral system, whose designs are fully described at www.openmaze.org. Whisking was monitored at $125 \mathrm{fps}$ with a camera (Sony PS3eye) and automatically tracked using published software (Clack et al., 2012).

\section{Intrinsic signal optical imaging and two-photon imaging}

Intrinsic signal optical imaging and two-photon imaging were performed on a Sutter movable objective microscope. The locations of whisker barrels in S1 were identified using intrinsic signal optical imaging. Single whiskers in isoflurane-anesthetized mice were stimulated at $5 \mathrm{~Hz}$ using a piezoelectric bimorph while recording the reflectance of 700-nm long-pass incandescent light with a Rolera CCD camera (QImaging) through a low-magnification objective (Zeiss 5X/0.16NA). Movies were collected using software custom-written in Labview (National Instruments). Regions of reflectance change were referenced to an image acquired under green illumination.

Two-photon imaging was conducted on the same microscope under the control of the ScanImage software package (V. Iyer, Janelia Farms). Scanning during awake conditions was performed at 30 fps using a Chameleon Ultra II laser (Coherent) tuned to $920 \mathrm{~nm}$, precompensated for group velocity dispersion and focused through a 20x/1.0NA water immersion lens (Zeiss). Emitted light was collected with an HQ535/50 filter (Chroma) and GaAsP photomultiplier tubes (Hamamatsu Photonics). Apical tuft tufts in Layer 1 were imaged at depths of 40-80 $\mu \mathrm{m}$ from the pial surface (433 x $433 \mu \mathrm{m}$ field of view, 512 x 512 pixels).

\section{SCAPE imaging}

High-speed volumetric imaging was performed using a custom SCAPE microscope as previously described (Bouchard et al., 2015; Hillman et al., 2018; Voleti et al., 2019). Briefly, the cortex was illuminated with an oblique light sheet through a Olympus XLUMPLFLN 20XW 1.0 NA water immersion objective with a 2-mm working distance. Fluorescence excited by this sheet (extending in the $y-z^{\prime}$ direction) was collected by the same objective lens. A galvanometer mirror in the system was positioned to both cause the oblique light sheet to scan from side to side across the sample (in the $x$ direction) but also to de-scan returning fluorescence light. This optical path results in an intermediate, de-scanned oblique image plane that is stationary yet always co-aligned with the plane in the sample that is being illuminated by the scanning light sheet. Image rotation optics and a fast sCMOS camera (Andor Zyla 4.2+) were then focused to capture these $y$ - $z^{\prime}$ images at $>1000$ frames per second as the sheet was repeatedly scanned across the cortex in the $x$ direction. All other system parts, including the objective and sample stage, were stationary during high-speed 3D image acquisition. Data were reformed into a 3D volume by stacking successive $y-z^{\prime}$ planes according to the scanning mirror's $x$ position and de-skewing to correct for the oblique sheet angle.

In this study, the stationary objective lens in SCAPE was configured on a manual rotation mount and set to $20^{\circ}-30^{\circ}$ away from the standard upright configuration, so the optical axis was perpendicular to the cranial window to achieve optimal performance without tilting the head of the animal. A 488-nm laser (Coherent OBIS) was used for excitation $(<10 \mathrm{~mW}$ at the sample) with a 500 -nm long-pass filter in the emission path. To achieve optimal spatiotemporal resolution and volume rate, the sample was imaged with an $x$-direction scanning step of $3 \mu \mathrm{m}$ over a $300 \times 1050$ $\times 234 \mu \mathrm{m}$ field of view $(x-y-z, 3.0 \times 1.40 \times 1.17 \mu \mathrm{m}$ per pixel $)$ at 10 volumes per second (VPS). 
919

920

921

922

923

924

925

926

927

928

929

930

931

932

933

934

935

936

937

938

939

940

941

942

943

944

945

946

947

948

949

950

951

952

953

954

955

956

957

958

959

960

961

962

963

964

965

966

967

968

\section{Analysis}

Two-photon movies were motion corrected using the NormCorre package (Pnevmatikakis and Giovannucci, 2017) in MATLAB. Spatial and temporal components for individual tufts imaged by two-photon and SCAPE were segmented using CaImAn, which employs large-scale sparse nonnegative matrix factorization (Giovannucci et al., 2019; Pnevmatikakis et al., 2016). CaImAn inherently corrects for background signal. All further analyses used custom-written routines implemented in MATLAB. Spatial components with tuft structural characteristics were identified and analyzed, while neuropil components were discarded.

To quantify a tuft's response to stimuli, the mean stimulus-aligned $\Delta \mathrm{F} / \mathrm{F}$ was computed across all $\mathrm{CS}+$ or CS- trials and corrected by the mean $\Delta \mathrm{F} / \mathrm{F}$ of the second before the trial. Probability of transients was obtained by taking each trial's $\Delta \mathrm{F} / \mathrm{F}$ in the first 1.5 seconds following either the CS+ or CS- and fitting these data with a univariate mixture of two Normal distributions: $(1-p) \mathrm{N}\left(\mu_{1}, \sigma_{1}\right)$ $+p \mathrm{~N}\left(\mu_{2}, \sigma_{2}\right)$. The smaller Normal reflects the distribution of failures, and the larger Normal the distribution of transient amplitudes following the stimulus. The parameter $p$ captures the probability of transients.

From these data, a selectivity index (SI) was defined as $\left(\mathrm{F}_{\mathrm{CS}+}-\mathrm{F}_{\mathrm{CS}-}\right) /\left(\mathrm{F}_{\mathrm{CS}+}+\mathrm{F}_{\mathrm{CS}-}\right)$, in which $\mathrm{F}_{\mathrm{CS}+}$ and $\mathrm{F}_{\mathrm{CS}}$ are the mean stimulus-aligned amplitudes $(\Delta \mathrm{F} / \mathrm{F})$ to the $\mathrm{CS}+$ and $\mathrm{CS}$ - within the first 1.5 seconds, respectively. This yielded values that range from -1 (exclusively CS- responsive) to 1 (exclusively CS + responsive). Neural discriminability was defined as $\mathrm{d}^{\prime}=\left|\mathrm{F}_{\mathrm{CS}+}-\mathrm{F}_{\mathrm{CS}-}\right| / \sqrt{ }\left(\left(\sigma_{\mathrm{CS}^{+}}+\right.\right.$

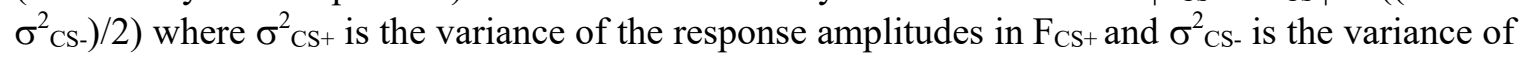
the response amplitudes in $\mathrm{F}_{\mathrm{CS}-}$.

For longitudinal analysis, tufts were categorized as stimulus responsive if they met two criteria: 1) Across all trials, the mean $\Delta \mathrm{F} / \mathrm{F} 1.5$ seconds before and 1.5 seconds after the stimulus were significantly different according to the Wilcoxon rank sum test, for either the CS+ or CS-, and 2) the average response amplitude for that stimulus was greater than $0.04 \Delta \mathrm{F} / \mathrm{F}$. Tufts with a significant response to only one stimulus were categorized as highly selective and their $|\mathrm{SI}|$ was set to 1 . To classify tufts as behaviorally modulated, the mean $\Delta \mathrm{F} / \mathrm{F}$ of the first 1.5 seconds after the stimulus was computed for false alarm and correct rejection trials and compared with a rank sum test. Only sessions with at least 12 false alarm trials were used for this analysis. If the two distributions were significantly different, the tuft was classified as behaviorally modulated.

Custom MATLAB software was used to compute the median whisker angle, and whisking amplitude was computed as described previously (Petty et al., 2020). The median angle was bandpass filtered from 4 to $30 \mathrm{~Hz}$ and passed through a Hilbert transform to calculate phase. We defined the upper and lower envelopes of the unfiltered median whisking angle as the points in the whisk cycle where phase equaled 0 (most protracted) or $\pi$ (most retracted), respectively. Whisking amplitude was defined as the difference between these two envelopes. Periods of whisking were defined as times where whisking amplitude exceeded $20 \%$ of maximum for at least $250 \mathrm{msec}$. Periods of time where amplitude exceeded this threshold for less than $250 \mathrm{msec}$ were considered ambiguous and excluded from analysis of whisking versus quiescence. The whisking-triggered average for each tuft was computed by aligning the calcium signal to the start times of whisking periods during inter-trial intervals (2-8 seconds after stimulus delivery).

For the linear regression analysis, we excerpted the calcium timeseries 2 seconds before and 6 seconds after each stimulus onset. The whisking amplitude signal was frame aligned to the calcium signal according to the lag of the calcium-whisking cross-correlation peak for each tuft. Whisking amplitude was then normalized to the max, yielding values that ranged from 0 to 1 . The stimulus 
969 predictor variable was a binary vector with an 800 -msec 'on' period ( 24 frames) centered at the

970 stimulus time. The timing of the stimulus variable was then aligned to the calcium signal according

971 to the latency of peak of the mean $\Delta \mathrm{F} / \mathrm{F}$ of the first 1.5 seconds relative to the stimulus. The lick

972 predictor variable was a binary vector with 'on' periods denoting lick bouts. Lick bouts were

973 defined as periods of time where the mouse elicited at least 2 licks, with a maximum gap of 200

$974 \mathrm{msec}$, and therefore had variable lengths.

975 
976

977

978

979

980

981

982

983

984

985

986

987

988

989

990

991

992

993

994

995

996

997

998

999

1000

1001

1002

1003

1004

1005

1006

1007

1008

1009

1010

1011

1012

1013

1014

1015

1016

1017

1018

1019

1020

1021

1022

1023

1024

1025

1026

\section{References}

Amitai, Y., Friedman, A., Connors, B.W., and Gutnick, M.J. (1993). Regenerative activity in apical dendrites of pyramidal cells in neocortex. Cereb Cortex 3, 26-38.

Banerjee, A., Parente, G., Teutsch, J., Lewis, C., Voigt, F.F., and Helmchen, F. (2020). Valueguided remapping of sensory cortex by lateral orbitofrontal cortex. Nature 585, 245-250.

Beaulieu-Laroche, L., Toloza, E.H.S., Brown, N.J., and Harnett, M.T. (2019). Widespread and Highly Correlated Somato-dendritic Activity in Cortical Layer 5 Neurons. Neuron 103, 235-241 e234.

Beitel, R.E., Schreiner, C.E., Cheung, S.W., Wang, X., and Merzenich, M.M. (2003). Rewarddependent plasticity in the primary auditory cortex of adult monkeys trained to discriminate temporally modulated signals. Proc Natl Acad Sci U S A 100, 11070-11075.

Berger, T.K., Silberberg, G., Perin, R., and Markram, H. (2010). Brief bursts self-inhibit and correlate the pyramidal network. PLoS Biol 8.

Bernhard, S.M., Lee, J., Zhu, M., Hsu, A., Erskine, A., Hires, S.A., and Barth, A.L. (2020). An automated homecage system for multiwhisker detection and discrimination learning in mice. PLoS One 15, e0232916.

Bittner, K.C., Milstein, A.D., Grienberger, C., Romani, S., and Magee, J.C. (2017). Behavioral time scale synaptic plasticity underlies CA1 place fields. Science 357, 1033-1036.

Bouchard, M.B., Voleti, V., Mendes, C.S., Lacefield, C., Grueber, W.B., Mann, R.S., Bruno, R.M., and Hillman, E.M. (2015). Swept confocally-aligned planar excitation (SCAPE) microscopy for high speed volumetric imaging of behaving organisms. Nature photonics 9, 113119.

Bouret, S., and Sara, S.J. (2004). Reward expectation, orientation of attention and locus coeruleus-medial frontal cortex interplay during learning. Eur J Neurosci 20, 791-802.

Brombas, A., Fletcher, L.N., and Williams, S.R. (2014). Activity-dependent modulation of layer 1 inhibitory neocortical circuits by acetylcholine. J Neurosci 34, 1932-1941.

Bruno, R.M., Khatri, V., Land, P.W., and Simons, D.J. (2003). Thalamocortical angular tuning domains within individual barrels of rat somatosensory cortex. J Neurosci 23, 9565-9574. Bruno, R.M., and Sakmann, B. (2006). Cortex is driven by weak but synchronously active thalamocortical synapses. Science 312, 1622-1627.

Cauller, L.J., Clancy, B., and Connors, B.W. (1998). Backward cortical projections to primary somatosensory cortex in rats extend long horizontal axons in layer I. J Comp Neurol 390, 297310.

Chen, T.W., Wardill, T.J., Sun, Y., Pulver, S.R., Renninger, S.L., Baohan, A., Schreiter, E.R., Kerr, R.A., Orger, M.B., Jayaraman, V., et al. (2013). Ultrasensitive fluorescent proteins for imaging neuronal activity. Nature 499, 295-300.

Chu, M.W., Li, W.L., and Komiyama, T. (2016). Balancing the Robustness and Efficiency of Odor Representations during Learning. Neuron 92, 174-186.

Chubykin, A.A., Roach, E.B., Bear, M.F., and Shuler, M.G. (2013). A cholinergic mechanism for reward timing within primary visual cortex. Neuron $77,723-735$.

Cichon, J., and Gan, W.B. (2015). Branch-specific dendritic $\mathrm{Ca}(2+)$ spikes cause persistent synaptic plasticity. Nature 520, 180-185.

Clack, N.G., O'Connor, D.H., Huber, D., Petreanu, L., Hires, A., Peron, S., Svoboda, K., and Myers, E.W. (2012). Automated tracking of whiskers in videos of head fixed rodents. PLoS Comput Biol 8, e1002591.

Constantinople, C.M., and Bruno, R.M. (2013). Deep cortical layers are activated directly by thalamus. Science 340, 1591-1594.

Dabney, W., Kurth-Nelson, Z., Uchida, N., Starkweather, C.K., Hassabis, D., Munos, R., and Botvinick, M. (2020). A distributional code for value in dopamine-based reinforcement learning. Nature 577, 671-675. 
1027

1028

1029

1030

1031

1032

1033

1034

1035

1036

1037

1038

1039

1040

1041

1042

1043

1044

1045

1046

1047

1048

1049

1050

1051

1052

1053

1054

1055

1056

1057

1058

1059

1060

1061

1062

1063

1064

1065

1066

1067

1068

1069

1070

1071

1072

1073

1074

1075

1076

1077

David, S.V., Fritz, J.B., and Shamma, S.A. (2012). Task reward structure shapes rapid receptive field plasticity in auditory cortex. Proc Natl Acad Sci U S A 109, 2144-2149.

de Kock, C.P., and Sakmann, B. (2009). Spiking in primary somatosensory cortex during natural whisking in awake head-restrained rats is cell-type specific. Proc Natl Acad Sci U S A 106, 16446-16450.

Derdikman, D., Yu, C., Haidarliu, S., Bagdasarian, K., Arieli, A., and Ahissar, E. (2006). Layerspecific touch-dependent facilitation and depression in the somatosensory cortex during active whisking. J Neurosci 26, 9538-9547.

Dragoi, V., Sharma, J., Miller, E.K., and Sur, M. (2002). Dynamics of neuronal sensitivity in visual cortex and local feature discrimination. Nat Neurosci 5, 883-891.

Dragoi, V., Sharma, J., and Sur, M. (2000). Adaptation-induced plasticity of orientation tuning in adult visual cortex. Neuron 28, 287-298.

Feldman, D.E., and Brecht, M. (2005). Map plasticity in somatosensory cortex. Science 310, 810815.

Feldmeyer, D. (2012). Excitatory neuronal connectivity in the barrel cortex. Front Neuroanat 6, 24.

Francioni, V., Padamsey, Z., and Rochefort, N.L. (2019). High and asymmetric somato-dendritic coupling of V1 layer 5 neurons independent of visual stimulation and locomotion. Elife 8.

Freedman, R., Foote, S.L., and Bloom, F.E. (1975). Histochemical characterization of a neocortical projection of the nucleus locus coeruleus in the squirrel monkey. J Comp Neurol 164, 209-231.

Fritz, J., Shamma, S., Elhilali, M., and Klein, D. (2003). Rapid task-related plasticity of spectrotemporal receptive fields in primary auditory cortex. Nat Neurosci 6, 1216-1223. Froemke, R.C., Merzenich, M.M., and Schreiner, C.E. (2007). A synaptic memory trace for cortical receptive field plasticity. Nature 450, 425-429.

Gasselin, C., Hohl, B., Vernet, A., Crochet, S., and Petersen, C.C.H. (2021). Cell-type-specific nicotinic input disinhibits mouse barrel cortex during active sensing. Neuron.

Giovannucci, A., Friedrich, J., Gunn, P., Kalfon, J., Brown, B.L., Koay, S.A., Taxidis, J., Najafi, F., Gauthier, J.L., Zhou, P., et al. (2019). CaImAn an open source tool for scalable calcium imaging data analysis. Elife 8.

Glickfeld, L.L., Andermann, M.L., Bonin, V., and Reid, R.C. (2013). Cortico-cortical projections in mouse visual cortex are functionally target specific. Nat Neurosci 16, 219-226.

Goltstein, P.M., Coffey, E.B., Roelfsema, P.R., and Pennartz, C.M. (2013). In vivo two-photon $\mathrm{Ca} 2+$ imaging reveals selective reward effects on stimulus-specific assemblies in mouse visual cortex. J Neurosci 33, 11540-11555.

Hangya, B., Ranade, S.P., Lorenc, M., and Kepecs, A. (2015). Central Cholinergic Neurons Are Rapidly Recruited by Reinforcement Feedback. Cell 162, 1155-1168.

Henschke, J.U., Dylda, E., Katsanevaki, D., Dupuy, N., Currie, S.P., Amvrosiadis, T., Pakan, J.M.P., and Rochefort, N.L. (2020). Reward Association Enhances Stimulus-Specific Representations in Primary Visual Cortex. Curr Biol 30, 1866-1880 e1865.

Hillman, E.M., Voleti, V., Patel, K., Li, W., Yu, H., Campos, C.P., Benezra, S.E., Bruno, R., and Galwaduge, P.T. (2018). High-speed 3D imaging of cellular activity in the brain using axiallyextended beams and light sheets. Curr Opin Neurobiol 50, 190-200.

Kapfer, C., Glickfeld, L.L., Atallah, B.V., and Scanziani, M. (2007). Supralinear increase of recurrent inhibition during sparse activity in the somatosensory cortex. Nat Neurosci 10, 743-753. Kim, J., Erskine, A., Cheung, J.A., and Hires, S.A. (2020). Behavioral and Neural Bases of Tactile Shape Discrimination Learning in Head-Fixed Mice. Neuron 108, 953-967 e958. Kozorovitskiy, Y., Saunders, A., Johnson, C.A., Lowell, B.B., and Sabatini, B.L. (2012). Recurrent network activity drives striatal synaptogenesis. Nature 485, 646-650.

Krauzlis, R.J., Lovejoy, L.P., and Zenon, A. (2013). Superior colliculus and visual spatial attention. Annu Rev Neurosci 36, 165-182. 
Labarrera, C., Deitcher, Y., Dudai, A., Weiner, B., Kaduri Amichai, A., Zylbermann, N., and London, M. (2018). Adrenergic Modulation Regulates the Dendritic Excitability of Layer 5 Pyramidal Neurons In Vivo. Cell Rep 23, 1034-1044. Learning Recruits Somata and Apical Dendrites across Layers of Primary Sensory Cortex. Cell Rep 26, 2000-2008 e2002. Larkum, M. (2013). A cellular mechanism for cortical associations: an organizing principle for the cerebral cortex. Trends Neurosci 36, 141-151. tuft dendrites of layer 5 pyramidal neurons: a new unifying principle. Science 325, 756-760. Larkum, M.E., Senn, W., and Luscher, H.R. (2004). Top-down dendritic input increases the gain of layer 5 pyramidal neurons. Cereb Cortex 14, 1059-1070.

1090 Larkum, M.E., and Zhu, J.J. (2002). Signaling of layer 1 and whisker-evoked Ca2+ and Na+

1091 action potentials in distal and terminal dendrites of rat neocortical pyramidal neurons in vitro and 1092 in vivo. J Neurosci 22, 6991-7005.

1093 Larkum, M.E., Zhu, J.J., and Sakmann, B. (2001). Dendritic mechanisms underlying the coupling of the dendritic with the axonal action potential initiation zone of adult rat layer 5 pyramidal 1095 neurons. J Physiol 533, 447-466.

1096 Letzkus, J.J., Wolff, S.B., Meyer, E.M., Tovote, P., Courtin, J., Herry, C., and Luthi, A. (2011). A disinhibitory microcircuit for associative fear learning in the auditory cortex. Nature 480, 331-

1098335.

1099 Liu, D., Deng, J., Zhang, Z., Zhang, Z.Y., Sun, Y.G., Yang, T., and Yao, H. (2020). Orbitofrontal control of visual cortex gain promotes visual associative learning. Nat Commun 11, 2784. Ljungberg, T., Apicella, P., and Schultz, W. (1992). Responses of monkey dopamine neurons during learning of behavioral reactions. J Neurophysiol 67, 145-163.

Llinas, R., Ribary, U., Contreras, D., and Pedroarena, C. (1998). The neuronal basis for consciousness. Philos Trans R Soc Lond B Biol Sci 353, 1841-1849.

Luebke, J.I., Weaver, C.M., Rocher, A.B., Rodriguez, A., Crimins, J.L., Dickstein, D.L., Wearne, S.L., and Hof, P.R. (2010). Dendritic vulnerability in neurodegenerative disease: insights from analyses of cortical pyramidal neurons in transgenic mouse models. Brain Struct Funct 214, 181199.

Manita, S., Miyakawa, H., Kitamura, K., and Murayama, M. (2017). Dendritic Spikes in Sensory Perception. Front Cell Neurosci 11, 29.

Manita, S., Suzuki, T., Homma, C., Matsumoto, T., Odagawa, M., Yamada, K., Ota, K., Matsubara, C., Inutsuka, A., Sato, M., et al. (2015). A Top-Down Cortical Circuit for Accurate Sensory Perception. Neuron 86, 1304-1316.

Mechawar, N., Cozzari, C., and Descarries, L. (2000). Cholinergic innervation in adult rat cerebral cortex: a quantitative immunocytochemical description. J Comp Neurol 428, 305-318. Naka, A., and Adesnik, H. (2016). Inhibitory Circuits in Cortical Layer 5. Front Neural Circuits 10,35 .

Nakamura, S., Narumi, T., Tsutsui, K., and Iijima, T. (2009). Difference in the functional significance between the lemniscal and paralemniscal pathways in the perception of direction of single-whisker stimulation examined by muscimol microinjection. Neuroscience research 64 , 323-329.

Oberlaender, M., de Kock, C.P., Bruno, R.M., Ramirez, A., Meyer, H.S., Dercksen, V.J., Helmstaedter, M., and Sakmann, B. (2012). Cell type-specific three-dimensional structure of thalamocortical circuits in a column of rat vibrissal cortex. Cereb Cortex 22, 2375-2391. Pakan, J.M.P., Currie, S.P., Fischer, L., and Rochefort, N.L. (2018). The Impact of Visual Cues, Reward, and Motor Feedback on the Representation of Behaviorally Relevant Spatial Locations in Primary Visual Cortex. Cell Rep 24, 2521-2528. 
1128

1129

1130

1131

1132

1133

1134

1135

1136

1137

1138

1139

1140

1141

1142

1143

1144

1145

1146

1147

1148

1149

1150

1151

1152

1153

1154

1155

1156

1157

1158

1159

1160

1161

1162

1163

1164

1165

1166

1167

1168

1169

1170

1171

1172

1173

1174

1175

1176

1177
Palmer, L.M., Shai, A.S., Reeve, J.E., Anderson, H.L., Paulsen, O., and Larkum, M.E. (2014). NMDA spikes enhance action potential generation during sensory input. Nat Neurosci 17, 383390.

Pan, W.X., Schmidt, R., Wickens, J.R., and Hyland, B.I. (2005). Dopamine cells respond to predicted events during classical conditioning: evidence for eligibility traces in the rewardlearning network. J Neurosci 25, 6235-6242.

Park, J.M., Hong, Y.K., Rodgers, C.C., Dahan, J.B., Schmidt, E.R., and Bruno, R.M. (2020).

Deep and superficial layers of the primary somatosensory cortex are critical for whisker-based texture discrimination in mice. bioRxiv, 2020.2008.2012.245381.

Parvizi, J., and Damasio, A. (2001). Consciousness and the brainstem. Cognition 79, 135-160.

Petersen, C.C., and Crochet, S. (2013). Synaptic computation and sensory processing in neocortical layer 2/3. Neuron 78, 28-48.

Petreanu, L., Gutnisky, D.A., Huber, D., Xu, N.L., O'Connor, D.H., Tian, L., Looger, L., and Svoboda, K. (2012). Activity in motor-sensory projections reveals distributed coding in somatosensation. Nature 489, 299-303.

Petty, G.H., Kinnischtzke, A.K., Hong, Y.K., and Bruno, R.M. (2020). Effects of arousal and movement on secondary somatosensory and visual thalamus. bioRxiv, 2020.2003.2004.977348. Pnevmatikakis, E.A., and Giovannucci, A. (2017). NoRMCorre: An online algorithm for piecewise rigid motion correction of calcium imaging data. J Neurosci Methods 291, 83-94. Pnevmatikakis, E.A., Soudry, D., Gao, Y., Machado, T.A., Merel, J., Pfau, D., Reardon, T., Mu, Y., Lacefield, C., Yang, W., et al. (2016). Simultaneous Denoising, Deconvolution, and Demixing of Calcium Imaging Data. Neuron 89, 285-299.

Poort, J., Khan, A.G., Pachitariu, M., Nemri, A., Orsolic, I., Krupic, J., Bauza, M., Sahani, M., Keller, G.B., Mrsic-Flogel, T.D., et al. (2015). Learning Enhances Sensory and Multiple Nonsensory Representations in Primary Visual Cortex. Neuron 86, 1478-1490.

Ramirez, A., Pnevmatikakis, E.A., Merel, J., Paninski, L., Miller, K.D., and Bruno, R.M. (2014). Spatiotemporal receptive fields of barrel cortex revealed by reverse correlation of synaptic input. Nat Neurosci 17, 866-875.

Rigotti, M., Barak, O., Warden, M.R., Wang, X.J., Daw, N.D., Miller, E.K., and Fusi, S. (2013). The importance of mixed selectivity in complex cognitive tasks. Nature 497, 585-590.

Rodgers, C.C., Nogueira, R., Pil, B.C., Greeman, E.A., Park, J.M., Hong, Y.K., Fusi, S., and Bruno, R.M. (2021). Sensorimotor strategies and neuronal representations for shape discrimination. Neuron 109, 2308-2325 e2310.

Roelfsema, P.R., and Holtmaat, A. (2018). Control of synaptic plasticity in deep cortical networks. Nat Rev Neurosci 19, 166-180.

Rubio-Garrido, P., Perez-de-Manzo, F., Porrero, C., Galazo, M.J., and Clasca, F. (2009).

Thalamic input to distal apical dendrites in neocortical layer 1 is massive and highly convergent. Cereb Cortex 19, 2380-2395.

Sandler, M., Shulman, Y., and Schiller, J. (2016). A Novel Form of Local Plasticity in Tuft Dendrites of Neocortical Somatosensory Layer 5 Pyramidal Neurons. Neuron 90, 1028-1042.

Schiller, J., Schiller, Y., Stuart, G., and Sakmann, B. (1997). Calcium action potentials restricted to distal apical dendrites of rat neocortical pyramidal neurons. J Physiol 505 ( Pt 3), 605-616.

Schwindt, P., and Crill, W. (1999). Mechanisms underlying burst and regular spiking evoked by dendritic depolarization in layer 5 cortical pyramidal neurons. J Neurophysiol 81, 1341-1354. Sheffield, M.E., and Dombeck, D.A. (2015). Calcium transient prevalence across the dendritic arbour predicts place field properties. Nature 517, 200-204.

Stringer, C., Pachitariu, M., Steinmetz, N., Carandini, M., and Harris, K.D. (2019). Highdimensional geometry of population responses in visual cortex. Nature 571, 361-365.

Takahashi, N., Ebner, C., Sigl-Glockner, J., Moberg, S., Nierwetberg, S., and Larkum, M.E. (2020). Active dendritic currents gate descending cortical outputs in perception. Nat Neurosci. 
Takahashi, N., Oertner, T.G., Hegemann, P., and Larkum, M.E. (2016). Active cortical dendrites modulate perception. Science 354, 1587-1590. Thiele, A., and Bellgrove, M.A. (2018). Neuromodulation of Attention. Neuron 97, 769-785. Tsai, J., Grutzendler, J., Duff, K., and Gan, W.B. (2004). Fibrillar amyloid deposition leads to local synaptic abnormalities and breakage of neuronal branches. Nat Neurosci 7, 1181-1183. Voleti, V., Patel, K.B., Li, W., Perez Campos, C., Bharadwaj, S., Yu, H., Ford, C., Casper, M.J., Yan, R.W., Liang, W., et al. (2019). Real-time volumetric microscopy of in vivo dynamics and large-scale samples with SCAPE 2.0. Nat Methods 16, 1054-1062. Wang, P.Y., Boboila, C., Chin, M., Higashi-Howard, A., Shamash, P., Wu, Z., Stein, N.P., Abbott, L.F., and Axel, R. (2020). Transient and Persistent Representations of Odor Value in Prefrontal Cortex. Neuron 108, 209-224 e206. Projection Column and Architecture of VPM and POm Axons in Rat Vibrissal Cortex. Cereb

1191 Cortex 20, 2265-2276.

1192 Xu, N.L., Harnett, M.T., Williams, S.R., Huber, D., O'Connor, D.H., Svoboda, K., and Magee,

1193 J.C. (2012). Nonlinear dendritic integration of sensory and motor input during an active sensing 1194 task. Nature 492, 247-251.

1195 Yamashita, T., Vavladeli, A., Pala, A., Galan, K., Crochet, S., Petersen, S.S.A., and Petersen, 1196 C.C.H. (2018). Diverse Long-Range Axonal Projections of Excitatory Layer 2/3 Neurons in 1197 Mouse Barrel Cortex. Front Neuroanat 12, 33.

1198 Yao, H., and Dan, Y. (2001). Stimulus timing-dependent plasticity in cortical processing of 1199 orientation. Neuron 32, 315-323.

1200 Yu, Y.S., Graff, M.M., Bresee, C.S., Man, Y.B., and Hartmann, M.J. (2016a). Whiskers aid 1201 anemotaxis in rats. Sci Adv 2, e1600716.

1202 Yu, Y.S., Graff, M.M., and Hartmann, M.J. (2016b). Mechanical responses of rat vibrissae to 1203 airflow. J Exp Biol 219, 937-948.

1204 Yuste, R., Gutnick, M.J., Saar, D., Delaney, K.R., and Tank, D.W. (1994). Ca2+ accumulations 1205 in dendrites of neocortical pyramidal neurons: an apical band and evidence for two functional 1206 compartments. Neuron 13, 23-43. Zhang, W., and Bruno, R.M. (2019). High-order thalamic inputs to primary somatosensory cortex are stronger and longer lasting than cortical inputs. eLife 8. 
bioRxiv preprint doi: https://doi.org/10.1101/2021.11.10.468144; this version posted November 11,2021 . The copyright holder for this preprint (which was not certified by peer review) is the author/funder, who has granted bioRxiv a license to display the preprint in perpetuity. It is made available under aCC-BY-NC-ND 4.0 International license.
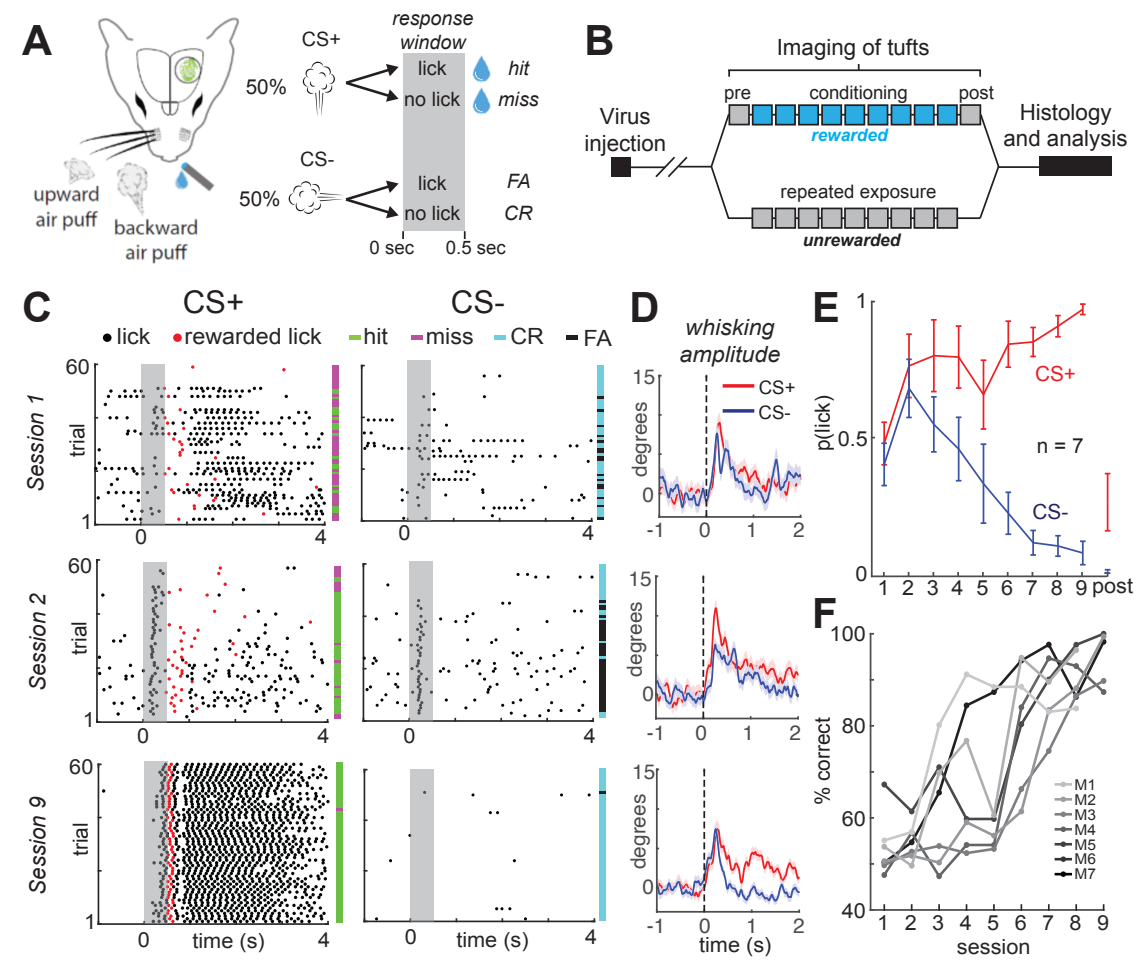

Figure 1. Mice rapidly learn to discriminate stimulus direction in head-fixed paradigm.

(A) A water droplet is paired with air puffs in one direction (CS+) but not the other (CS-). Licking in anticipation of water is assessed in the response window just after CS+ or CSand prior to water delivery for the CS+ (grey bar).

(B) Experimental timeline. 2-3 weeks after virus injection, naive tuft responses to stimuli are recorded (pre). The CS+ is then paired with water for 8-9 days (blue). On the last day, stimuli are presented without reward (post). In a separate group of mice, the same stimuli are presented over 9 days in the absence of reward (unrewarded group).

(C) Lick rasters for three different sessions in one example mouse. On session 9, the CS+ but not the CS- reliably elicits licks.

(D) Mean baseline-subtracted whisking amplitude aligned to the CS+ (red) and CS- (navy) across sessions 1,2 , and 9 of an example mouse.

(E) Learning curve demonstrates rapid learning. Mean probability of at least one lick in the response window across sessions.

(F) Behavioral performance of each mouse in the rewarded group (M1 - M7). 
bioRxiv preprint doi: https://doi.org/10.1101/2021.11.10.468144; this version posted November 11,2021 . The copyright holder for this preprint (which was not certified by peer review) is the author/funder, who has granted bioRxiv a license to display the preprint in perpetuity. It is made available under aCC-BY-NC-ND 4.0 International license.
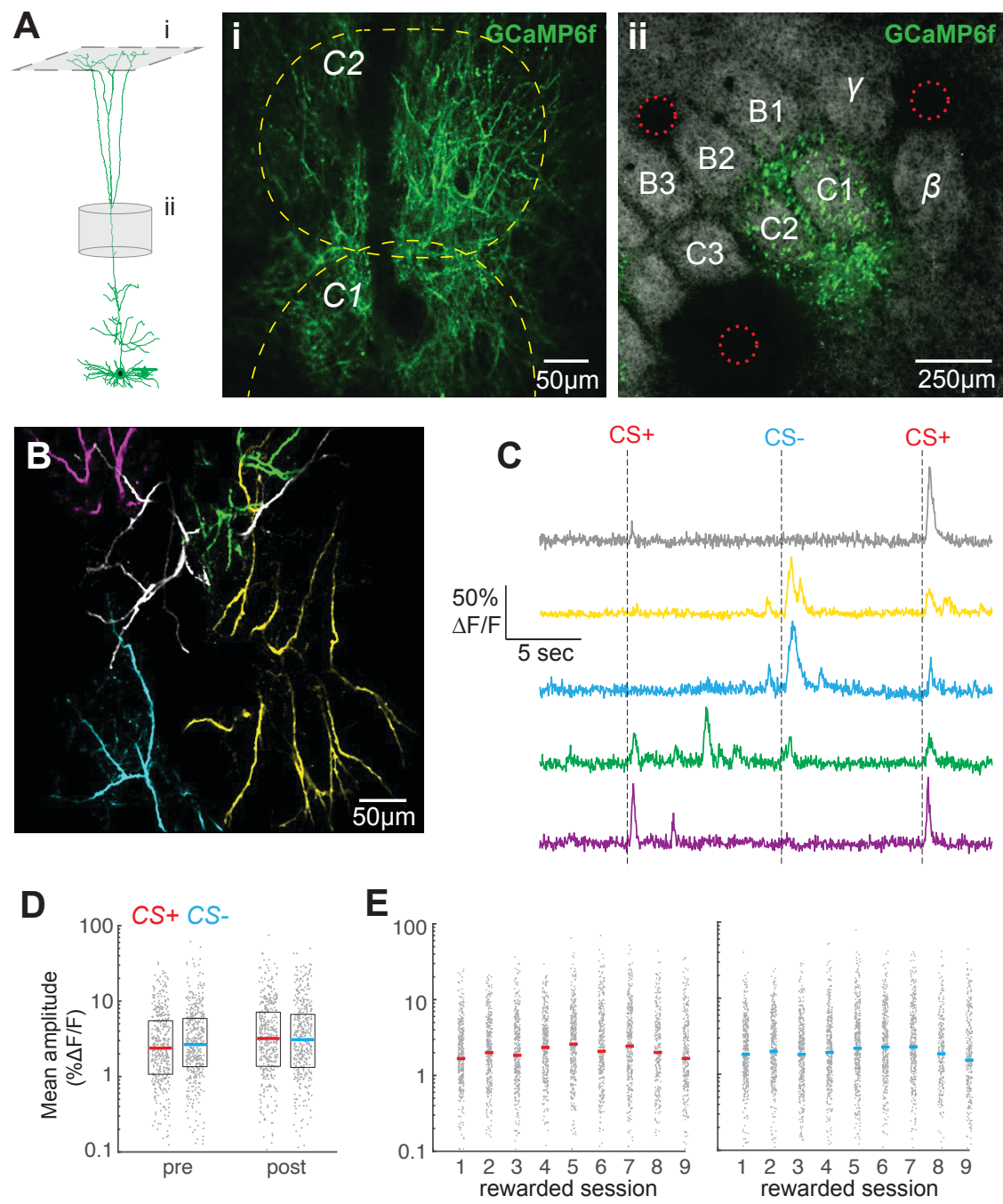

Figure 2. Overall tuft response to stimuli is unbiased and relatively stable across conditioning.

(A) Dendritic activity was recorded in layer 1 (i) in the $\mathrm{C} 1 / \mathrm{C} 2$ barrel columns (ii). (i) Two-photon image $\sim 60 \mu \mathrm{m}$ deep relative to pia. Dashed yellow lines denote C1 and C2 boundaries from intrinsic imaging. Reconstruction from (Ramirez et al., 2014).

(ii) Tangential section through layer 4 showing barrels stained with streptavidin-Alexa 647 and GCaMP6f-expressing apical trunks. Red circles indicate location of 2-photon lesions to mark the imaging region for post-hoc analysis.

(B) Overlay of five segmented pseudo-colored tufts from imaging field in A(i).

(C) Time courses of calcium responses of example tufts in (B) to three air puffs (dashes).

(D) Amplitude for CS+ (red) and CS- responses (blue), computed for each segmented tuft in the first $1.5 \mathrm{~s}$ post-stimulus (grey points), do not differ within or across sessions. Colored lines indicate median.

(E) Same as in D, showing data for all conditioning sessions. 
bioRxiv preprint doi: https://doi.org/10.1101/2021.11.10.468144; this version posted November 11,2021 . The copyright holder for this preprint (which was not certified by peer review) is the author/funder, who has granted bioRxiv a license to display the preprint in perpetuity. It is made available under aCC-BY-NC-ND 4.0 International license.
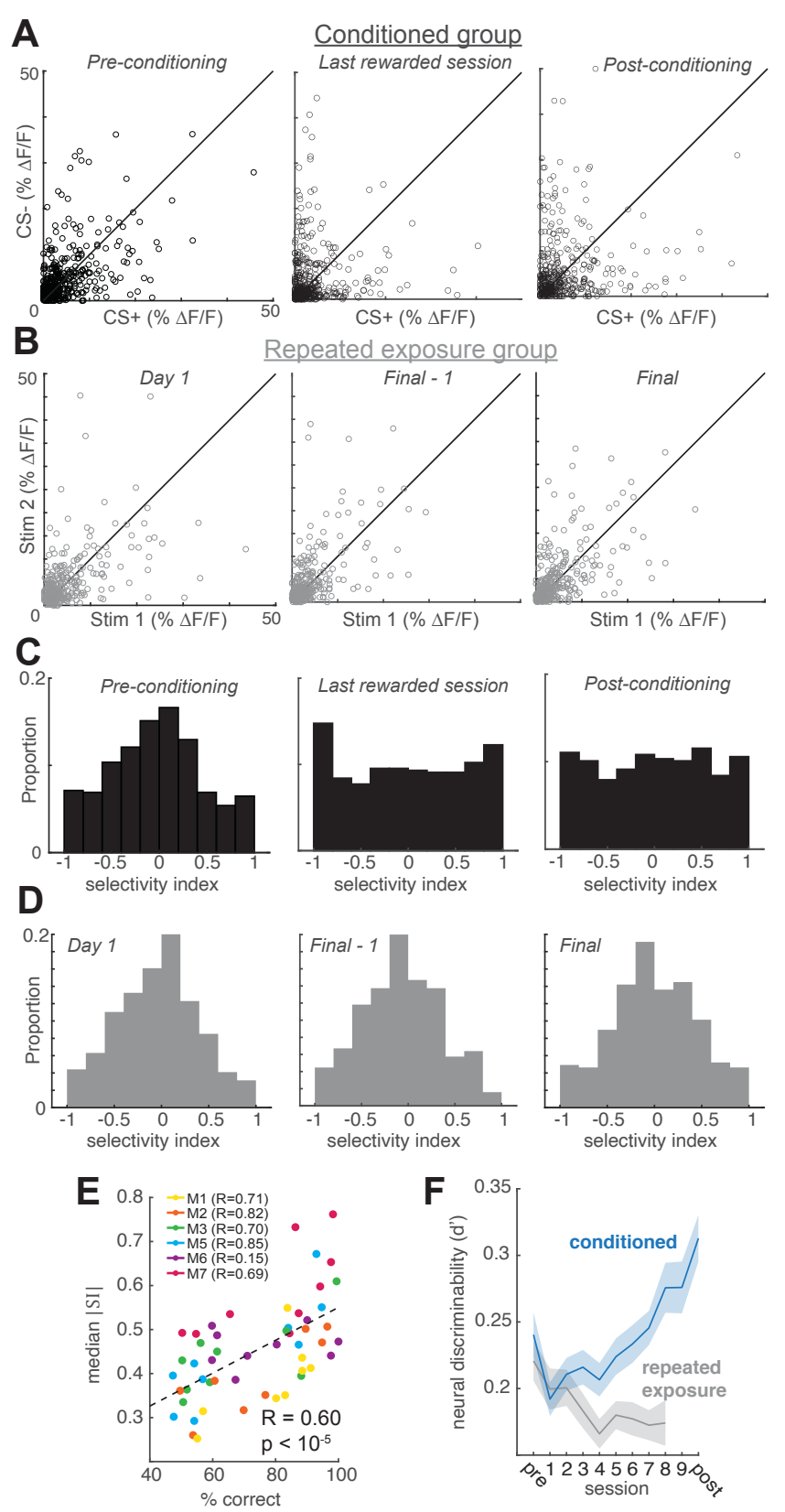

Figure 3. Reinforcement learning, but not stimulus exposure, enhances tuft selectivity for CS+ and CS- stimuli.

(A) Across the indicated sessions, individual tufts (circles) exhibit larger biases to CS+ or CS- (pooled across all conditioned mice).

(B) Repeated exposure to stimuli does not bias individual tufts to CS+ or CS-.

(C) Conditioning reshapes distribution of selectivity indices for tufts from Normal on pre-conditioning session to uniform on post-conditioning session.

(D) Distribution of tuft selectivity indices remains Normal throughout all repeated exposure sessions.

(E) Selectivity (median SI magnitude of tufts for each session) increases with behavioral performance of 6 animals.

(F) Neural discriminability (mean \pm sem) of tufts, pooled across all animals on each session, increases with conditioning and decreases with repeated exposure. 
bioRxiv preprint doi: https://doi.org/10.1101/2021.11.10.468144; this version posted November 11,2021 . The copyright holder for this preprint (which was not certified by peer review) is the author/funder, who has granted bioRxiv a license to display the preprint in perpetuity. It is made available under aCC-BY-NC-ND 4.0 International license.
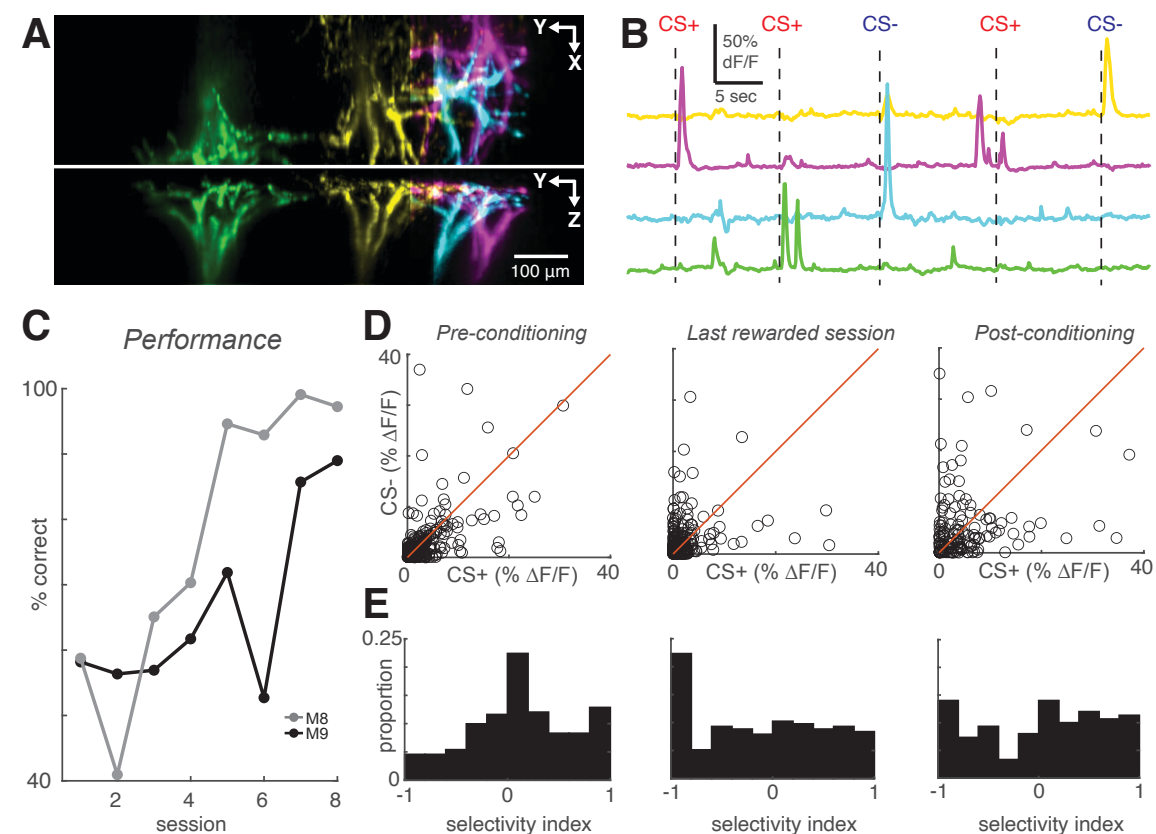

E
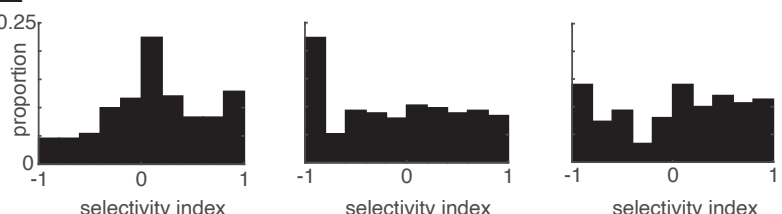

Figure 4. High-speed volumetric imaging of apical tufts confirms the emergence of enhanced selectivity after learning.

(A) Top and side view of four example tufts segmented from volumetric SCAPE imaging.

(B) Time courses of calcium activity from example tufts in (A) during five presentations of air puff stimuli (dashes).

(C) Performance across all conditioning sessions of two mice that were imaged with SCAPE.

(D) Across the indicated sessions, individual SCAPE-imaged tufts (circles) exhibit larger biases to CS+ or CS-.

(E) Conditioning reshapes selectivity distribution from Normal to uniform. 
bioRxiv preprint doi: https://doi.org/10.1101/2021.11.10.468144; this version posted November 11,2021 . The copyright holder for this preprint (which was not certified by peer review) is the author/funder, who has granted bioRxiv a license to display the preprint in perpetuity. It is made available under aCC-BY-NC-ND 4.0 International license.
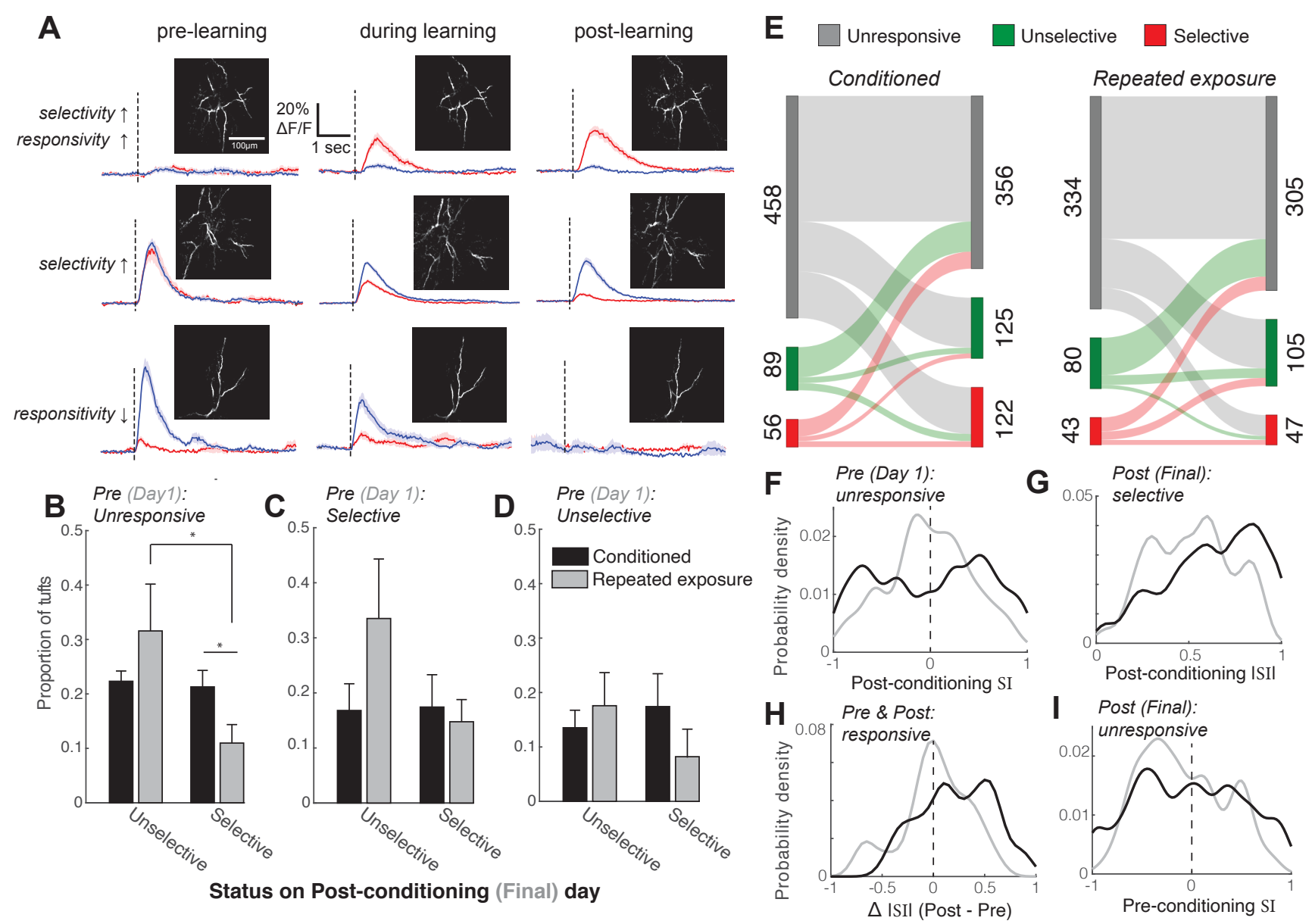

Figure 5. Longitudinal tracking reveals that reward enhances the selectivity of both initially unresponsive and responsive tufts.

(A) Three example tufts that were longitudinally tracked across learning. Top row: An initially unresponsive tuft develops a robust response to the CS+ but not the CS- after learning. Middle row: A responsive but unselective tuft loses its robust CS+ response and becomes selective for the CS-. Bottom row: A CS- selective neuron becomes unresponsive to both stimuli.

(B) Tufts that were unresponsive during the first session were longitudinally tracked to the last session. Plotted is the mean proportion of selective and unselective neurons across all animals in the conditioned (black bars) and repeated exposure (grey bars) groups.

$(C, D)$ Same analysis as $C$ for initially selective (D) and unselective (E) tufts.

Two-sample t-test was used for comparisons between conditioned and repeated exposure groups. Paired t-test was used for comparisons within a group. * $\mathrm{p}<0.05$

(E) Total tuft counts from first to last session within the 3 response categories for either conditioned (left) or repeated exposure (right) groups.

(F) SI of responsive tufts on the last session that were initially unresponsive during the first session. Conditioned tufts have enhanced selectivity compared to repeated exposure.

(G) Tufts that were selective on the last session are more selective if conditioned (black) rather than undergoing repeated exposure (grey).

(H) Tufts that responded on both pre and post sessions tend to have higher selectivity if conditioned rather than undergoing repeated exposure.

(I) SI of responsive tufts on the first session that later became unresponsive during the last session. 
bioRxiv preprint doi: https://doi.org/10.1101/2021.11.10.468144; this version posted November 11,2021 . The copyright holder for this preprint (which was not certified by peer review) is the author/funder, who has granted bioRxiv a license to display the preprint in perpetuity. It is made available under aCC-BY-NC-ND 4.0 International license.

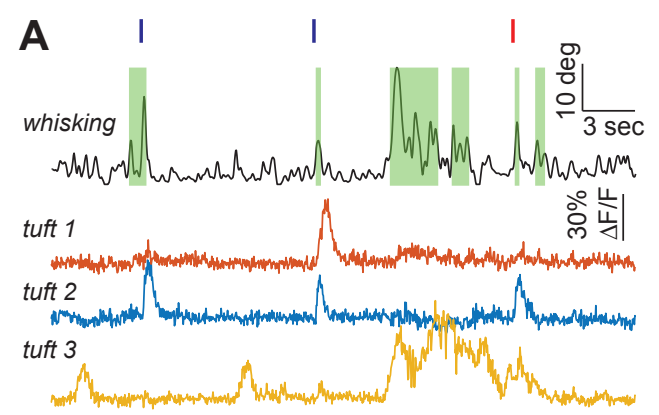

B

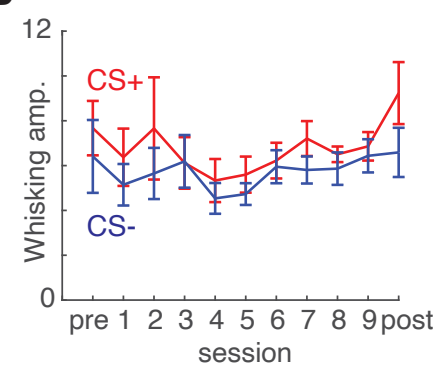

C

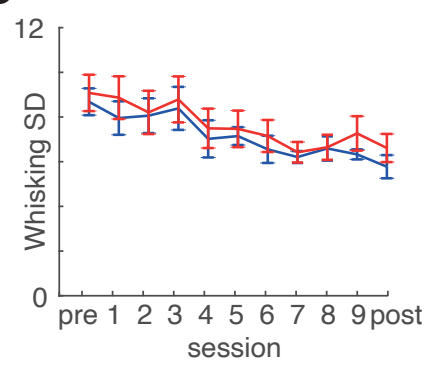

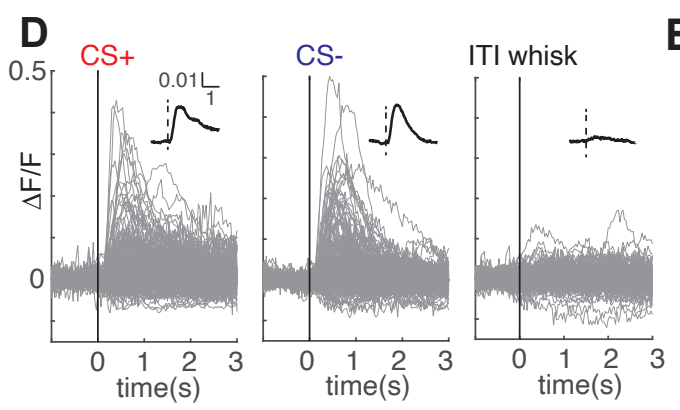
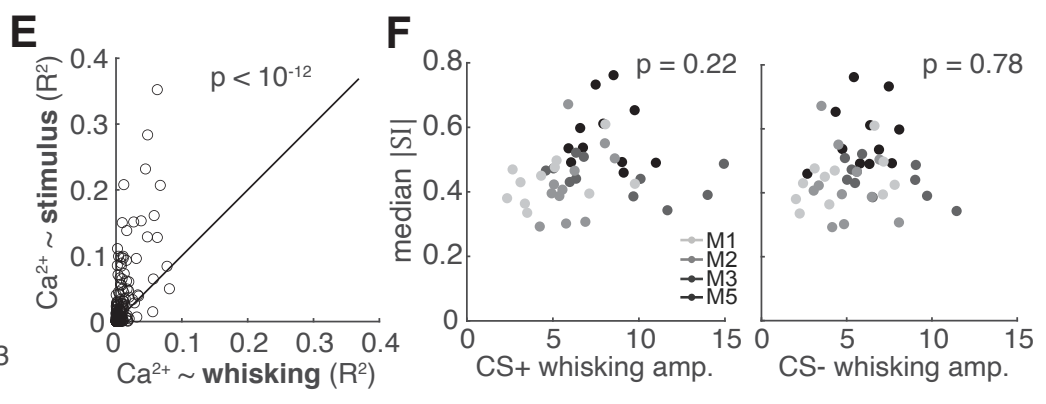

Figure 6. Whisking is only weakly correlated with tuft activity and cannot account for changes in selectivity during learning.

(A) Whisking amplitude aligned to calcium activity of three example tufts in one session. Green shading indicates periods of whisking. Red and navy ticks indicate CS+ or CSdelivery, respectively.

(B) Mean whisking response of four mice to CS+ (red) and CS- (navy) does not change across sessions during learning (mean \pm s.e.m.).

(C) Mean standard deviation of whisking decreases for both CS+ and CS- across learning, but CS+ and CS- do not differ.

(D) Event-triggered averages of 322 tufts on the post-conditioning day (grey traces individual tufts, black inset - population average) are responsive to stimuli but relatively unmodulated by whisking.

(E) R2 values for linear models predicting calcium from stimuli (y axis) are consistently greater than those predicting calcium from whisking ( $x$ axis). Each circle represents a tuft. (F) Magnitude of tuft selectivity does not correlate with mean whisking amplitude during CS+ (left) and CS- trials (right) on that session. 
bioRxiv preprint doi: https://doi.org/10.1101/2021.11.10.468144; this version posted November 11,2021 . The copyright holder for this preprint (which was not certified by peer review) is the author/funder, who has granted bioRxiv a license to display the preprint in perpetuity. It is made available under aCC-BY-NC-ND 4.0 International license.

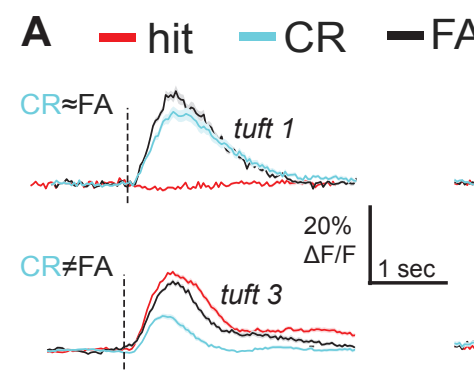

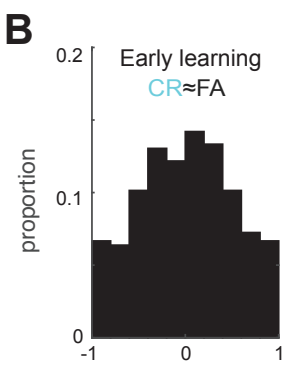

SI

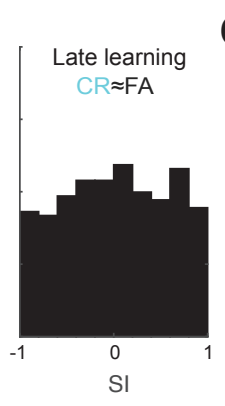

Figure 7. Behavioral responses do not account for enhancement of stimulus selectivity during learning.

(A) Mean stimulus responses of four tufts during hit (red), CR (cyan), and FA (black) trials. Top row: Example tufts whose responses are not behaviorally modulated (CR is similar to FA). Bottom row: Example tufts with behaviorally modulated responses (CR and FA differ).

(B) Selectivity index (SI) distribution changes from early (left) and late learning sessions (right) even when tufts with behaviorally modulated responses $(C R \neq F A)$ are excluded. (C) Median SI magnitude of tufts in each of six animals (from panel B) increases from early to late learning sessions. 
bioRxiv preprint doi: https://doi.org/10.1101/2021.11.10.468144; this version posted November 11,2021 . The copyright holder for this preprint (which was not certified by peer review) is the author/funder, who has granted bioRxiv a license to display the preprint in perpetuity. It is made available under aCC-BY-NC-ND 4.0 International license.

A

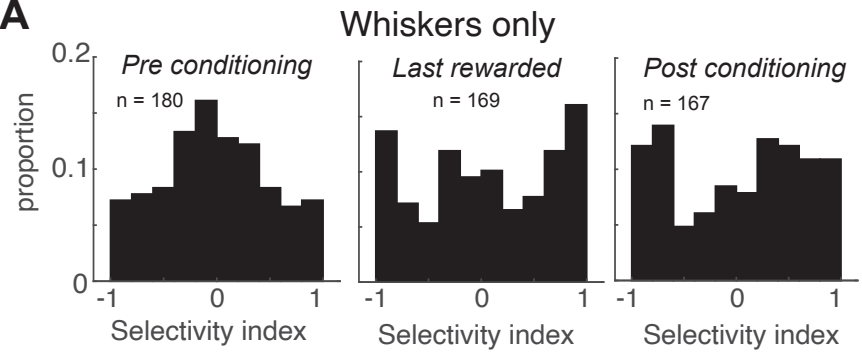

B

Whiskers + other senses
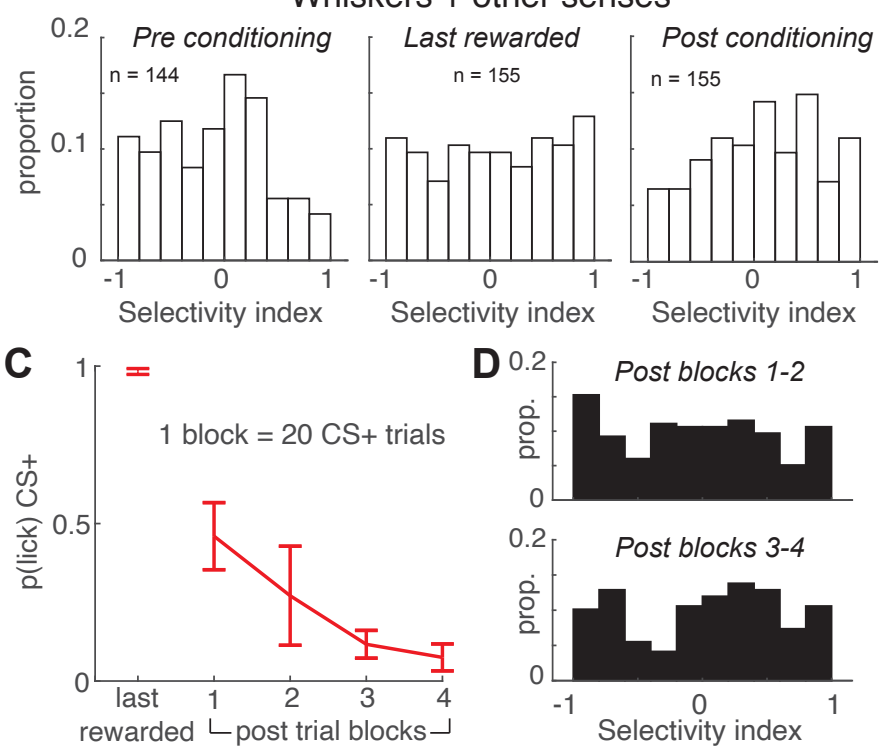

Figure 8. Apical tufts in barrel cortex of mice performing the task exclusively with their whiskers undergo long-lasting changes in selectivity.

(A) SI histograms of mice performing the task exclusively with their whiskers exhibit increased selectivity across pre-conditioning, last-rewarded, and post-conditioning sessions.

(B) Relative to pre-conditioning, mice using their whiskers and other sensory cues to perform the task have increased selectivity during the last rewarded session, but not the post-conditioning session.

(C) The probability of anticipatory licks in response to the CS+ extinguishes across post-conditioning blocks (of 20 trials each).

(D) Tuft selectively remains uniformly distributed during post-conditioning trial blocks 1-2 (top) while licking is extinguishing, and blocks 3-4 (bottom) in which licking is extinguished. 
bioRxiv preprint doi: https://doi.org/10.1101/2021.11.10.468144; this version posted November 11,2021 . The copyright holder for this preprint (which was not certified by peer review) is the author/funder, who has granted bioRxiv a license to display the preprint in perpetuity. It is made available under aCC-BY-NC-ND 4.0 International license.

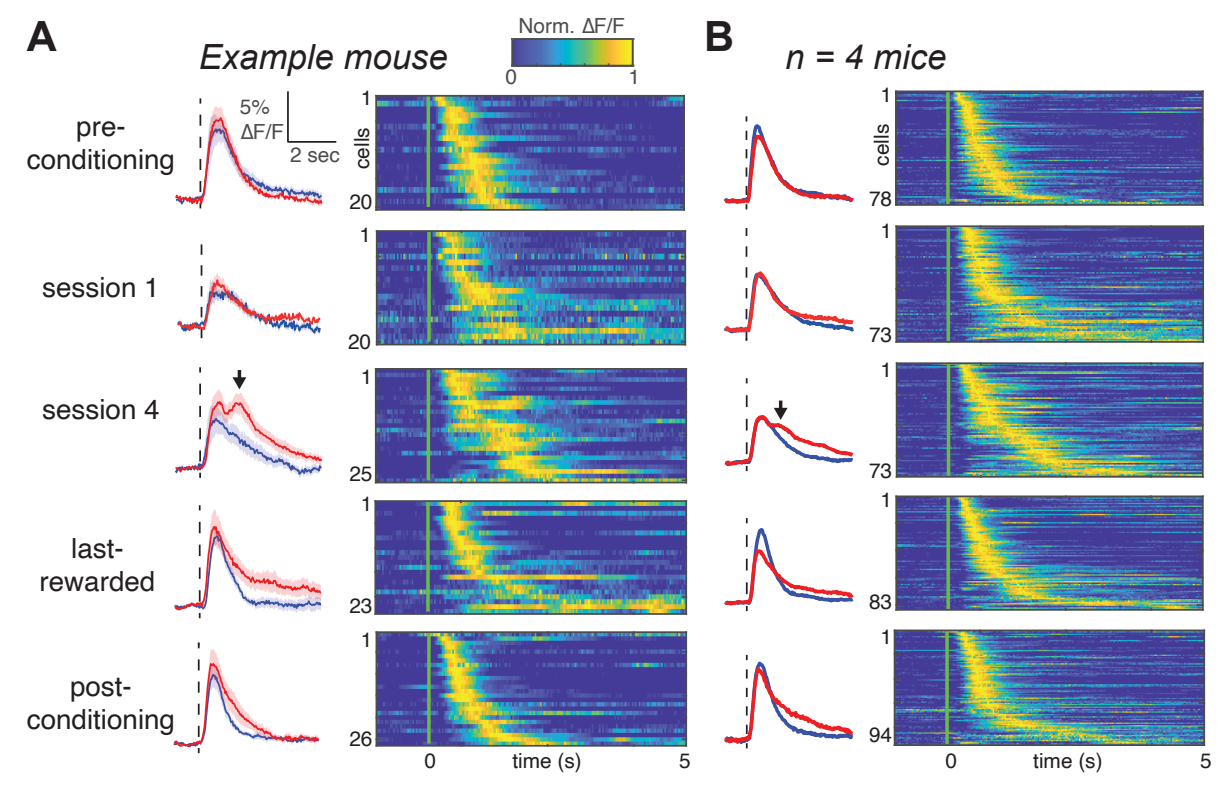

Supplementary Figure 1. CS+ trials evoke a second, long-latency peak during early learning, but not late learning.

(A) Left: Population average of stimulus-responsive tufts aligned to CS+ (red) or CS(blue) trials from an example mouse. Right: Normalized $\Delta F / F$ of individual tufts during $\mathrm{CS}+$ trials.

(B) Same as in A, combining data across four mice whose imaging regions were mapped with intrinsic imaging. 
bioRxiv preprint doi: https://doi.org/10.1101/2021.11.10.468144; this version posted November 11, 2021. The copyright holder for this preprint (which was not certified by peer review) is the author/funder, who has granted bioRxiv a license to display the preprint in perpetuity. It is made available under aCC-BY-NC-ND 4.0 International license.

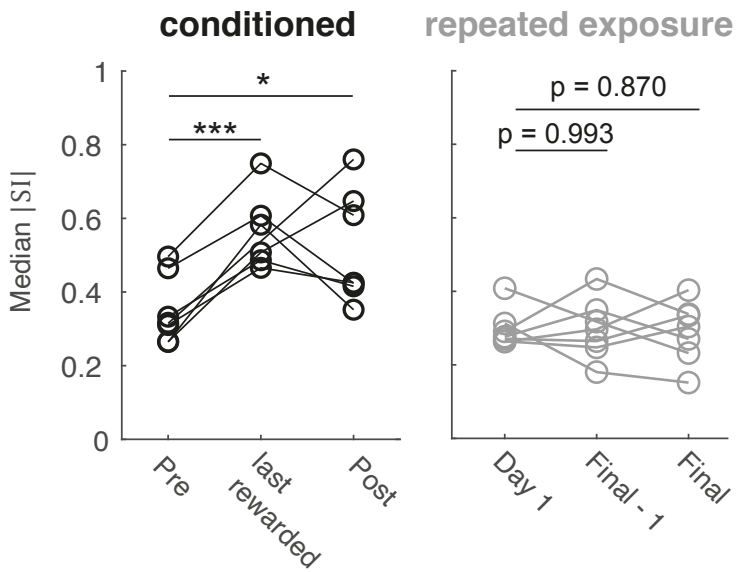

Supplementary Figure 2. Selectivity was enhanced in individual animals that received rewards.

Median SI magnitude for each animal across three sessions for conditioned (left) and repeated exposure groups (right). ${ }^{\star} p<0.05,{ }^{\star * \star} p<10^{-3}$ 
bioRxiv preprint doi: https://doi.org/10.1101/2021.11.10.468144; this version posted November 11,2021 . The copyright holder for this preprint (which was not certified by peer review) is the author/funder, who has granted bioRxiv a license to display the preprint in perpetuity. It is made available under aCC-BY-NC-ND 4.0 International license.
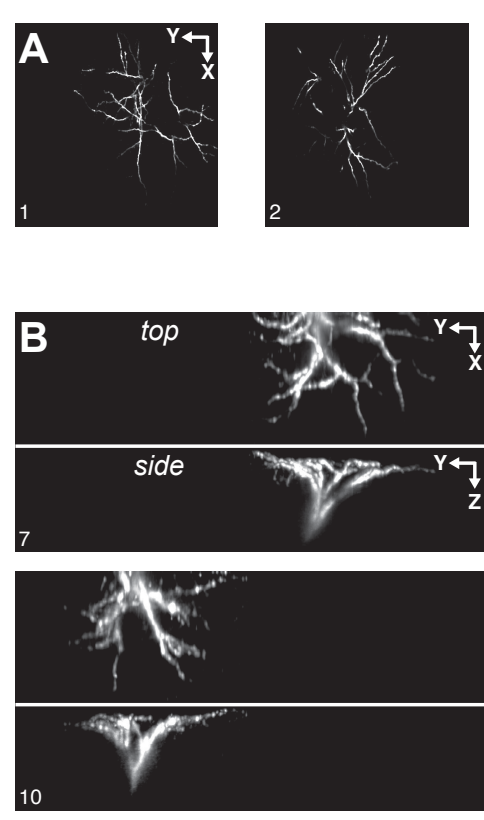

\section{Two-photon}
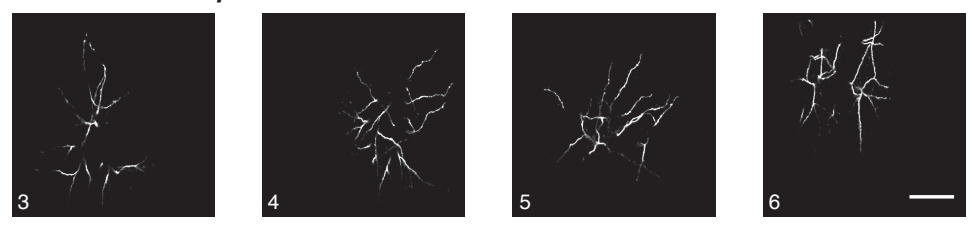

\section{SCAPE}
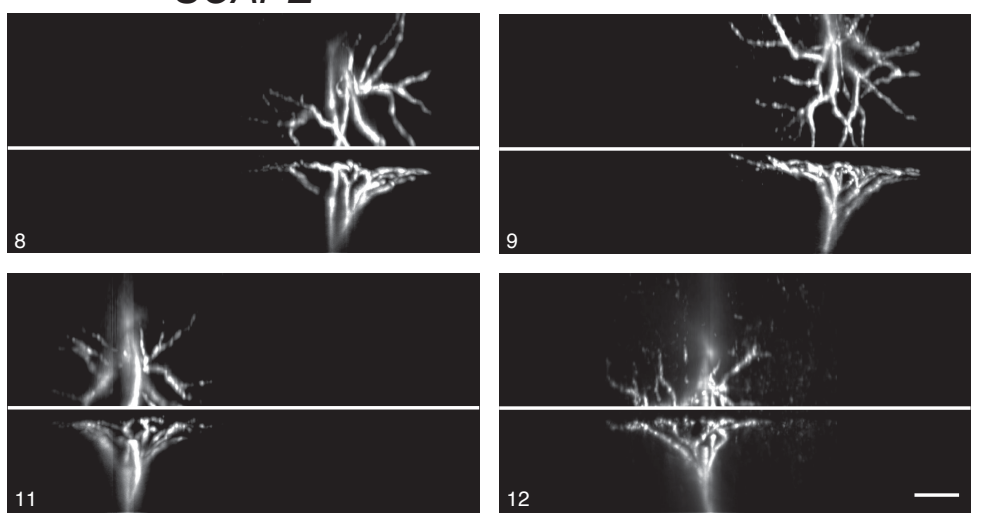

Supplementary Figure 3. Segmented tufts from two-photon and SCAPE microscopy.

$(A, B) 12$ example tufts extracted from either two-photon (A) or SCAPE microscopy (B). Tufts segmented from SCAPE microscopy are shown as maximum intensity projections from the top and side. Scale bars: $100 \mu \mathrm{m}$. 
bioRxiv preprint doi: https://doi.org/10.1101/2021.11.10.468144; this version posted November 11, 2021. The copyright holder for this preprint (which was not certified by peer review) is the author/funder, who has granted bioRxiv a license to display the preprint in perpetuity. It is made available under aCC-BY-NC-ND 4.0 International license.

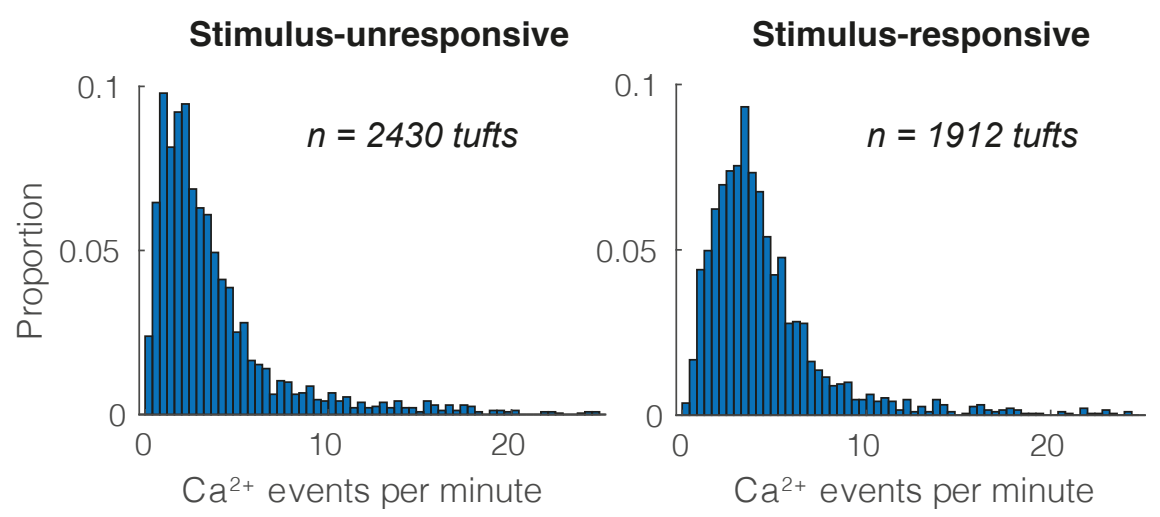

Supplementary Figure 4. Calcium event rate of tufts that were either unresponsive or responsive to air puff stimuli.

The number of calcium events per minute was quantified for all tufts during each conditioning session. Data from each group was pooled across all sessions. 
bioRxiv preprint doi: https://doi.org/10.1101/2021.11.10.468144; this version posted November 11,2021 . The copyright holder for this preprint (which was not certified by peer review) is the author/funder, who has granted bioRxiv a license to display the preprint in perpetuity. It is made available under aCC-BY-NC-ND 4.0 International license.

A

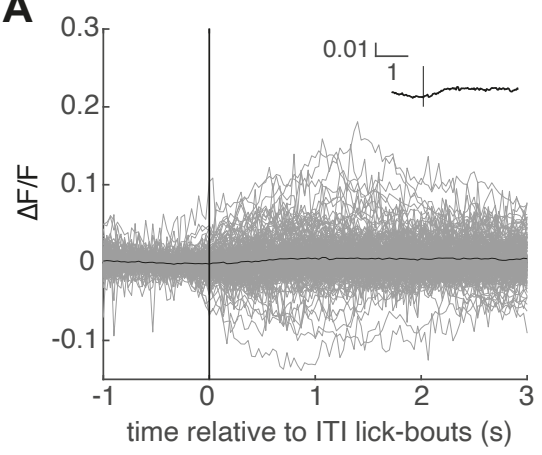

B

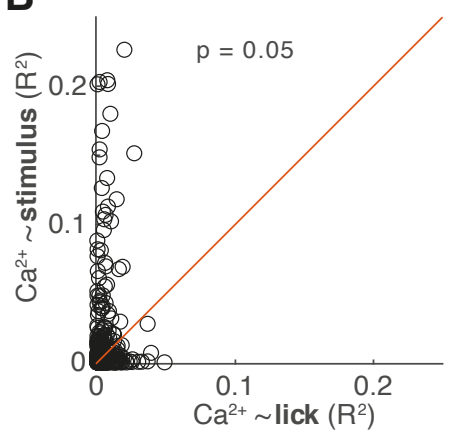

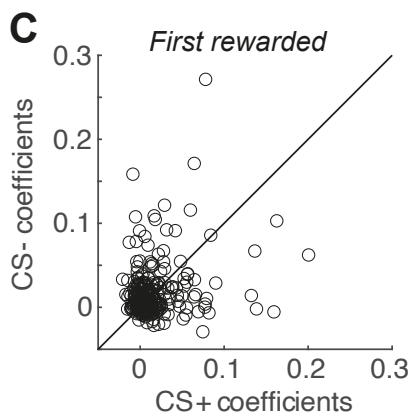
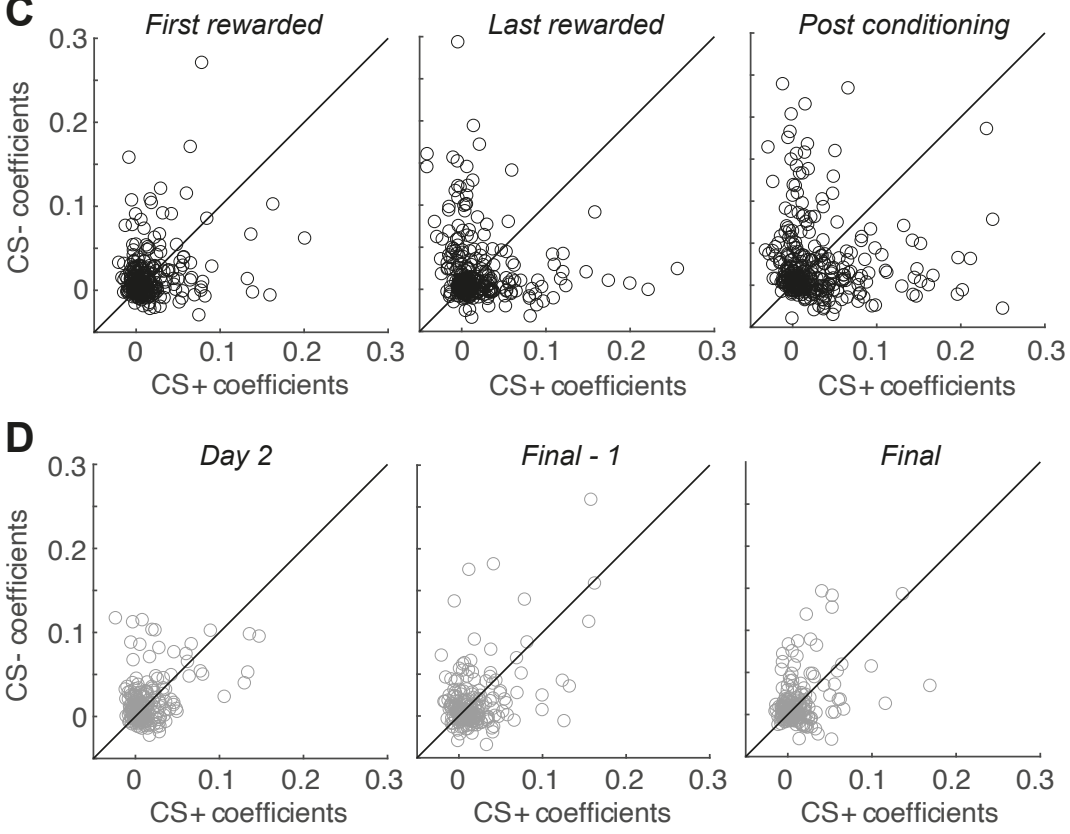

Supplementary Figure 5. Licking cannot account for changes in selectivity during learning.

(A) ITI lick-bout-triggered averages of 232 tufts on the 5th conditioning day, when ITI licks were still common (grey traces - individual tufts, black inset - population average), exhibit little or no lick-related calcium influx.

(B) R2 values for linear models predicting calcium from stimuli (y axis) are consistently greater than those predicting calcium from licking ( $x$ axis). Each circle represents one tuft out of 442 tufts on last-rewarded sessions.

(C) Coefficients from a multivariate regression analysis with calcium as the response variable and the CS+, CS-, whisking, and licking as the predictors. CS+ and CS- coefficients are therefore disentangled from correlations with whisking and licking. Conditioning biases individual tufts (circles) to have larger CS+ or CS- coefficients. $n=304,324$, and 322 tufts for First rewarded, Last rewarded, and Post conditioning, respectively.

(D) Similar analysis to $\mathrm{C}$ but for repeated exposure group, with calcium as the response variable and the CS+, CS-, and whisking as the predictors. $n=223,208$, and 218 tufts for Day 2, Final - 1, and Final session, respectively. 